\title{
BCMA peptide engineered nanoparticles enhance induction and function of antigen-specific CD8+ cytotoxic T lymphocytes against multiple myeloma: Clinical applications
}

\author{
Jooeun Bae ${ }^{1,2}$, Neha Parayath ${ }^{3}$, Wenxue $\mathrm{Ma}^{4}$, Mansoor Amiji ${ }^{5}$, Nikhil Munshi ${ }^{1,2}$, Kenneth \\ Anderson ${ }^{1,2}$ \\ ${ }^{1}$ Dana-Farber Cancer Institute, Boston, Massachusetts, USA. \\ ${ }^{2}$ Harvard Medical School, Boston, Massachusetts, USA. \\ ${ }^{3}$ Fred Hutchinson Cancer Research Center, Seattle, Washington, USA. \\ ${ }^{4}$ University of California San Diego, San Diego, California, USA. \\ ${ }^{5}$ Northeastern University, Boston, Massachusetts, USA.
}

\section{Abstract}

Objective: The purpose of these studies was to develop and characterize B-cell Maturation Antigen (BCMA)-specific peptide encapsulated nanoparticle formulations to efficiently evoke BCMA-specific $\mathrm{CD} 8^{+}$cytotoxic $\mathrm{T}$ lymphocytes (CTL) with poly-functional immune activities against multiple myeloma (MM).

Findings: Heteroclitic BCMA $72-80$ [Y LLMFLLRKI] peptide encapsulated liposome or poly(lactic-co-glycolic acid) (PLGA) nanoparticles displayed uniform size distribution and increased peptide delivery to human dendritic cells which enhanced induction of BCMA-specific CTL. Distinct from liposome-based nanoparticles, PLGA-based nanoparticles demonstrated a gradual increase in peptide uptake by antigen-presenting cells, and induced BCMA-specific CTL with higher anti-tumor activities (CD107a degranulation, CTL proliferation, and IFN- $\gamma / \mathrm{IL}-2 / \mathrm{TNF}-$ a production) against primary $\mathrm{CD} 138^{+}$tumor cells and $\mathrm{MM}$ cell lines. The improved functional activities were associated with increased Tetramer $^{+} / \mathrm{CD}_{4} 4 \mathrm{RO}^{+}$memory CTL, CD28 upregulation on Tetramer ${ }^{+} \mathrm{CTL}$, and longer maintenance of central memory $\left(\mathrm{CCR} 7^{+} \mathrm{CD} 45 \mathrm{RO}^{+}\right) \mathrm{CTL}$, with the highest anti-MM activity and less differentiation into effector memory $\left(\mathrm{CCR}^{-} \mathrm{CD}^{-} \mathrm{ROO}^{+}\right) \mathrm{CTL}$.

Conclusion: These results provide the framework for therapeutic application of PLGA-based BCMA peptide delivery system, rather than free peptide, to enhance the induction of BCMAspecific CTL with poly-functional Th1-specific anti-MM activities.

Corresponding author: Jooeun Bae, Ph.D., Dana-Farber Cancer Institute, Harvard Medical School, 450 Brookline Avenue, Boston, MA 02115, Phone: 617-632-5908, Fax: 617-632-2140, jooeun_bae@dfci.harvard.edu.

Conflict of Interest:

No relevant conflicts of interest were disclosed by the authors.

A conflict of interest disclosure statement:

There is no conflict of interest to disclose. 
Significance: These results demonstrate the potential clinical utility of PLGA nanotechnologybased cancer vaccine to enhance BCMA-targeted immunotherapy against myeloma.

\section{Keywords}

Nanomedicine-based Cancer Vaccine; Targeted Immunotherapy specific to BCMA

\section{INTRODUCTION}

Significant advances in cancer immunotherapy including immune checkpoint inhibition have achieved remarkable responses, changed the treatment paradigm, and improved patient outcome in many solid tumors. Chimeric antigen receptor (CAR) T-cell therapy has recently achieved great clinical response and has improved patient outcome in relapsed/refractory acute lymphocytic leukemia and diffuse large B cell lymphoma, leading to their FDA approval. However, current cellular therapies including CAR-T therapy require complex patient-specific protocols for engineering and expansion of effector cells, which are both labor-intensive and cost-ineffective. ${ }^{1-4}$ To overcome these limitations, successful development of an off-the-shelf cancer vaccine would be beneficial to treat patients efficiently over individualized cellular-based vaccines. As an active-specific immunotherapy, cancer vaccine approaches have the potential to modulate the tumor microenvironment through dynamic interaction of various cell subsets in the patients, which contribute to antigen-presentation, $\mathrm{T}$ cells activation, effector cells functionality and the specific memory CTL development. 5,6 With encouraging preclinical results, we are evaluating a multipeptide vaccine targeting XBP-1, CD138 and CS1 in the patients with smoldering multiple myeloma and have detected the antigens-specific immune responses as increased Tetramer ${ }^{+} /$memory $^{2}$ $\mathrm{CD} 8{ }^{+} \mathrm{CTL}$ with higher IFN- $\gamma / \mathrm{IL}-2 / \mathrm{TNF}-\mathrm{a}$ production. Moreover, combination of the multipeptide vaccine with lenalidomide enhanced the induction of $\mathrm{CD} 8^{+} \mathrm{CTL}$ with Tetramer-positivity and Th-1-specific memory CD8 ${ }^{+}$CTL. ${ }^{7-10}$ To date, clinical efficacy of vaccines has been limited, at least in part due to the need for improved methods for tumorassociated antigen (TAA) delivery, stability, biodistribution, and presentation for $\mathrm{T}$ cell activation. $^{11-13}$

MM is a B-cell malignancy characterized by the clonal proliferation and accumulation of malignant plasma cells in the bone marrow, monoclonal protein in the serum and/or urine, and development of osteolytic bone lesions. Despite remarkable recent advances in treatment using novel therapeutics, MM remains incurable. BCMA, a member of the tumor necrosis factor (TNF) receptor superfamily and the receptor for binding of B cell activating factor (BAFF) and the proliferation-inducing ligand (APRIL), ${ }^{14-16}$ is a promising therapeutic target for development of an immunotherapy due to its restricted expression on $\mathrm{MM}$ and plasma cells along and its critical role in promoting tumor cell growth, survival and drug resistance. At present, BCMA is being targeted by several immunotherapeutic strategies including monoclonal antibodies (mAbs), immunotoxins, bispecific T-cell engagers, and adoptive immunotherapy (e.g. CAR-T), with promising early results in the clinic. However, there remains significant need to improve BCMA targeted active-specific immunotherapy capable of inducing highly effective and long-lasting MM-specific CTL with a favorable therapeutic index. 
We recently identified a novel immunogenic heteroclitic BCMA $_{72-80}$ [YLMFLLRKI] peptide derived from human BCMA protein and reported its potential therapeutic application as a vaccine and adoptive T cell therapy. ${ }^{17}$ The engineered heteroclitic BCMA $_{72-80}$ [YLLMFLLRKI] peptide has a strong HLA-A2 binding affinity and stability with improved immunogenicity from its native $\mathrm{BCMA}_{72-80}$ [VLMFLLRKI] peptide and induces robust $\mathrm{BCMA}$-specific memory $\mathrm{CD} 8^{+} \mathrm{CTL}$ responses against MM cells. In this study, we have developed a strategy to further enhance BCMA-specific CTL generation and their antitumor activities, in order to achieve clinically significant responses. We define a nanoparticle-based BCMA delivery technology in which the heteroclitic $\mathrm{BCMA}_{72-80}$ [YLMFLLRKI] peptide is encapsulated in nanovehicles, either PLGA or liposome, to improve antigen delivery and presentation, thereby inducing more robust poly-functional BCMA-specific $\mathrm{CD}^{+} \mathrm{CTL}$ responses against MM than vaccination with peptide alone.

\section{METHODS}

\section{Cell lines and Reagents}

The MM cell lines were obtained from ATCC (Manassas, VA) and the T2 cell line was provided by Dr. J. Molldrem (University of Texas M. D. Anderson Cancer Center, Houston, TX). Recombinant human GM-CSF, IL-2, IL-4, IFN- $a$ and TNF- $a$ were purchased from Immunex (Seattle, WA) or R\&D Systems (Minneapolis, MN). Heteroclitic BCMA $72-80$ [YLMFLLRKI] peptide, unlabeled or FITC-labeled, were synthesized by standard fmoc (9fluorenylmethyl-oxycarbonyl) chemistry, purified to $>98 \%$ using reverse-phase chromatography and validated by mass-spectrometry for molecular weight (Biosynthesis, Lewisville, TX). Tetramer-PE specific to the heteroclitic $\mathrm{BCMA}_{72-80}$ peptide was synthesized by MBL International Corporation (Woburn, MA).

\section{Formulation and characterization of heteroclitic $\mathrm{BCMA}_{72-80}$ peptide encapsulated PLGA or liposome nanoparticles}

A double emulsion-solvent technique was used to formulate PLGA (molecular weight 23,000; Birmingham Polymers, Birmingham, AL) nanoparticles loaded with immunogenic heteroclitic BCMA 72-80 [YLMFLLRKI] peptide. Poly(vinyl alcohol) (PVA) (Sigma-Aldrich, St Louis, MO) was used to stabilize the emulsion, as previously described ${ }^{18}$ with some modifications. Following formulation of the PLGA formulation, the diameter and surface charge was measured using a Zetasizer Nano-ZS90 (Malvern Instruments; Westborough, MA) dynamic light scattering instrument. To evaluate PLGA-nanoparticle structure, the lyophilized powder was visualized under a scanning electron microscope (SEM) (S-4800; Hitachi, Schaumburg, IL) at the magnification of 50X. For BCMA peptide encapsulated liposome formulation, liposome lipid bilayer was prepared with a mixture of $3 \mathrm{mM}$ Cholesterol (MW = 386.654), $5 \mathrm{mM}$ DOPC (MW = 786.113), and $5 \mathrm{mM}$ DOTAP (MW = 698.542) (Avanti Polar, Alabaster, AL) in chloroform (Sigma-Aldrich) and evaporated using a rotary evaporator (RV10 IKA; Neobits, Santa Clara, CA) to yield a thin lipid film. The lipid film was subjected to overnight vacuum drying to remove any residual organic solvent. The next day, peptide dissolved in sodium phosphate buffer (dibasic; $\mathrm{pH} 11$ ) and 1\% DMSO (Sigma-Aldrich) was used to hydrate the lipid film using 10X freeze-thaw cycles, followed by probe sonication on ice and recovered by ultracentrifugation. Malvern's Zetasizer 
dynamic light scattering instrumentation was used to determine the liposome diameter.

Transmission electron microscopy (TEM) (JEM-1000, JEOL, Tokyo, Japan) was utilized to characterize the surface morphology of the BCMA peptide-loaded liposome after applying $2 \%$ uranyl acetate stain at the magnification of $20,000 \mathrm{X}$.

\section{Quantification of BCMA peptide encapsulation in PLGA or liposome nanoparticles}

The BCMA peptide encapsulation in nanoparticles was measured using the Quantitative Fluorometric Peptide Assay Kit (Thermo Fisher) per the manufacturer's instruction. The fluorescence was measured using a spectrophotometer (Molecular Devices, San Jose, CA) at $390 \mathrm{~nm}$ Excitation and $475 \mathrm{~nm}$ Emission wave lengths for the peptide quantification.

\section{Evaluation of BCMA peptide-encapsulated nanoparticles for peptide uptake by dendritic cells}

Monocyte-derived dendritic cells (DC) were generated as described previously. ${ }^{7-9}$ Immature DC $\left(1 \times 10^{6}\right.$ cells/well $)$ were pulsed with free BCMA peptide-FITC or the peptide-FITC encapsulated nanoparticles in the presence of human $\beta 2$-microglobulin $(3 \mu \mathrm{g} / \mathrm{ml})$ and incubated at $37^{\circ} \mathrm{C}$. Cells were washed, fixed in $2 \%$ paraformaldehyde, acquired using a LSRII Fortessa ${ }^{\mathrm{TM}}$ flow cytometer (Becton Dickinson (BD), San Jose, CA). The level of peptide loading was analyzed in a time-dependent manner using FACS DIVA ${ }^{\mathrm{TM}}$ v8.0 (BD) or FlowJo v10.0.7 (Tree star, Ashland, OR) software. The peptide uptake was also imaged by confocal microscopy (Nikon, Tokyo, Japan), upon fixation of the cells with $2 \%$ paraformaldehyde (Electron Microscopy Sciences, Hatfield, PA) and counter-stained with $300 \mathrm{nM}$ DAPI (Sigma-Aldrich) to identify cell nuclei.

\section{Generation of heteroclitic BCMA $72-80$ peptide-specific CTL}

Heteroclitic BCMA $_{72-80}$ peptide [YLMFLLRKI]-specific CTL (BCMA-specific CTL) were generated ex vivo by repeated stimulation of peripheral blood mononuclear cells (PBMC) isolated from six different HLA-A2 ${ }^{+}$normal donors with (1) free BCMA peptide, (2) BCMA peptide encapsulated PLGA (PLGA/peptide) or (3) BCMA peptide encapsulated liposome (liposome/peptide). The BCMA-specific effector cells were cultured in DMEM supplemented with $10 \%$ human $\mathrm{AB}$ serum (BioWhittaker) and examined after each cycle of weekly stimulation for a total of 4 or 5 cycles.

\section{Isolation of Primary CD138+ cells from Bone Marrow Mononuclear Cells of MM Patients}

Primary $\mathrm{CD} 138^{+}$cells were isolated from bone marrow mononuclear cells obtained from HLA-A2 ${ }^{+}$and HLA-A2 ${ }^{-}$MM patients using RoboSep ${ }^{\circledR}$ CD138 positive immunomagnetic selection technology (StemCell Technologies), after appropriate informed consent.

\section{Phenotypic characterization of BCMA-specific CTL induced with heteroclitic $\mathrm{BCMA}_{72-80}$ peptide encapsulated nanoparticles or free peptide}

BCMA-CTL were evaluated for antigen-specific Tetramer ${ }^{+}$memory CTL and CD28 expression by flow cytometry. In brief, following Live/Dead-Aqua staining, BCMA-CTL were stained with heteroclitic $\mathrm{BCMA}_{72-80}$ specific Tetramer-PE and flurochrome conjugated 
mAbs specific to surface antigens. Lastly, cells were washed, fixed in $2 \%$ paraformaldehyde, and analyzed by flow cytometry.

\section{Evaluation of anti-myeloma activities of BCMA-specific CTL induced with heteroclitic $B C_{72-80}$ peptide encapsulated nanoparticles or free peptide}

Proliferation of CFSE (Molecular Probes) labeled BCMA-specific CTL (CD8 ${ }^{+}$gated) was measured after co-culture with irradiated myeloma cells. On days 3-6 of co-culture, the cells were stained with specific mAbs, and acquired by flow cytometry. To measure anti-tumor activities, BCMA-CTL were mixed with the respective target in the presence of CD107a $\mathrm{mAb}$. After 1 hour of co-culture, Brefeldin A and Monensin (BD) were added and cultures were incubated for an additional 5 hours at $37^{\circ} \mathrm{C}$. Cells were harvested, stained with Live/ Dead-Aqua and fluorochrome conjugated $\mathrm{mAbs}$, fixed/permeabilized, and stained intracellularly with specific mAb against IFN- $\gamma$, IL-2 or TNF- $a$, acquired using a LSRII Fortessa $^{\mathrm{TM}}$ flow cytometer (BD) and analyzed using FACS DIVA ${ }^{\mathrm{TM}}$ v8.0 (BD) or FlowJo v10.0.7 (Tree star, Ashland, OR) software

\section{Statistical Analyses}

Summary results are presented as the mean \pm SE. Groups were compared using unpaired Student's t-test. Differences were considered significant when ${ }^{*} p<0.05$.

\section{RESULTS}

\section{Characterization and quantification of heteroclitic $\mathrm{BCMA}_{72-80}$ peptide encapsulated nanoparticles}

The size, zeta-potential and/or polydispersity index (PDI) of PLGA- or liposomenanoparticles, with or without heteroclitic $\mathrm{BCMA}_{72-80}$ [YLMFLLRKI] peptide, were measured using dynamic light scattering properties. Peptide loaded-PLGA (PLGA/peptide) $(257 \pm 11.53 \mathrm{~nm} ; \mathrm{N}=3)$ were slightly smaller than the blank PLGA (309 $\pm 4.01 \mathrm{~nm} ; \mathrm{N}=3)$, which can be attributed to a close interaction between PLGA co-polymer and the peptide (Figure 1A). The surface charge and zeta potential were measured as an important criteria for cellular uptake of peptide. Blank PLGA and PLGA/peptide had a near neutral zetapotential, $-0.66 \pm 0.25 \mathrm{mV}$ and $-1.16 \pm 0.18 \mathrm{mV}$, respectively. The peptide (positively charged at $\mathrm{pH}$ 7) would form the core of nanoparticles; while the near neutral surface charge is due to interaction with PLGA polymer, resulting in an increased stability due to a larger electrostatic repulsion between the nanoparticles. To evaluate size distribution, the blank PLGA or PLGA/peptide were sputter coated with gold/palladium and imaged using a scanning electron microscope under $20 \mathrm{kV}$ at the magnification of 50X. The PDI of PLGA/ peptide ( $\leq 0.2$ ) was similar to blank PLGA, which indicates uniform size distribution (Figure 1A). The BCMA peptide loaded-liposome formulation (liposome/peptide) had a size distribution of of $172 \pm 0.73 \mathrm{~d} . \mathrm{nm}(\mathrm{N}=3)$ as measured using a transmission electron microscope, with a PDI of $0.20 \pm 0.01$, reflecting uniform size distribution in the formulated product (Figure 1B). Next, peptide loading and encapsulation efficiency was evaluated with the Quantitative Fluorometric Peptide Assay, using a spectrophotometer at an Excitation wave length at $390 \mathrm{~nm}$ and an Emission wave length at $475 \mathrm{~nm}$. The peptide encapsulation efficiency (\%), which indicates the percentage of peptide loaded in PLGA or liposome over 
the initial amount of loaded peptide, was $51 \pm 1.15 \%$ and $49 \pm 1.32 \%$, respectively (Figure $1 \mathrm{C} ; \mathrm{N}=3$ ).

\section{Enhanced BCMA peptide uptake by dendritic cells upon nanoparticle encapsulation}

BCMA peptide uptake was evaluated after pulsing immature dendritic cells with free peptide-FITC, PLGA/peptide-FITC or liposome/peptide-FITC by flow cytometry. A higher level of peptide uptake $(* p<0.05)$ was detected for the encapsulated in either type of nanoparticles as compared to the free peptide, following a short (30 minutes - 2 hour, Figure $2 \mathrm{~A}$ ) or longer ( $1-18$ hour, Figure $2 \mathrm{~B} ; \mathrm{N}=3$ ) duration of peptide pulsing. Between the two different types of formulations, liposome/peptide showed a faster and higher efficiency of uptake than PLGA/peptide, which demonstrated a gradual increase in peptide loading over time (Figures 2A, 2B). In addition, confocal microscopy (magnitude: 10X) showed a higher peptide uptake with PLGA/peptide as compared to free peptide (Figure 2C), confirming that the nanoparticles formulation enhances BCMA peptide uptake by dendritic cells. Thus, these results demonstrate the beneficial effect of both types of nanoparticles to enhance the peptide loading efficiency to antigen-presenting cells, which is a crucial step prior to triggering development of antigen-specific CTL.

\section{Increased poly-functional immune responses by BCMA-specific CTL generated with peptide-encapsulated nanoparticles against myeloma cells}

Free BCMA peptide, PLGA/BCMA peptide or liposome/BCMA peptide was used to generate the BCMA peptide-specific CTL from six different HLA-A2 ${ }^{+}$normal donors to evaluate their anti-myeloma activities. The highest levels of anti-tumor activity were observed with PLGA/peptide-CTL as shown by increased CD107a degranulation (Figure $3 \mathrm{~A}$ ), IFN- $\gamma$ production (Figure 3B), IL-2 and TNF- $a$ production (Supplemental Fig. 1, Fig. 2) against HLA-A2 ${ }^{+}$U266 myeloma cells but not against MHC mis-matched HLA-A2RPMI myeloma cells. Further evaluations were performed using BCMA-CTL generated from additional three HLA-A2 $2^{+}$individuals and the results confirm the highest antimyeloma activities $(* p<0.05)$ against HLA-A2 ${ }^{+} \mathrm{BCMA}^{++}$(high) $\mathrm{U} 266$ and HLA-A2 ${ }^{+}$ $\mathrm{BCMA}^{+}{ }^{\text {(low) }} \mathrm{McCAR}$, but not against MHC mis-matched BCMA ${ }^{+}$RPMI cells by PLGA/ peptide-CTL (Figure 3C). The anti-myeloma activities of liposome/peptide-CTL were lower than PLGA/peptide-CTL but were greater than free peptide BCMA-CTL. These results indicate a robust generation of BCMA-specific CTL by PLGA/peptide as evidenced by their higher poly-functional activities against MM cell lines in an HLA-A2 restricted manner.

\section{The highest anti-tumor activity by BCMA-specific CTL generated with PLGA/peptide against primary $\mathrm{CD}_{138^{+}}$tumor cells from MM patients}

BCMA-specific CTL were further evaluated for their anti-myeloma activities against primary $\mathrm{CD} 138^{+}$tumor cells from newly diagnosed multiple myeloma patients. Background level of activity was measured in the BCMA-CTL in the absence of target cells (Supplemental Fig. 3). However, PLGA/peptide-CTL demonstrated higher anti-MM activities against primary $\mathrm{CD} 138^{+}$tumor cells from HLA-A2 ${ }^{+} \mathrm{MM}$ patients (patients $\# 1$ or \#2) as compared to liposome/peptide-CTL and free peptide-CTL (Figure 4A, Figure 4B). Furthermore, BCMA-specific CTL generated from three additional HLA-A2 ${ }^{+}$individuals confirmed the different degree of anti-MM activities; Significantly $\left({ }^{*} p<0.05\right)$ higher anti- 
myeloma activities were induced with peptide encapsulated nanoparticles (PLGA/peptide > liposome/peptide) than free peptide against $\mathrm{CD} 138^{+}$primary tumor cells from HLA-A2 ${ }^{+}$ MM patients (patients \#3 or \#4), but not against HLA-A2- MM patients (Figure 4C; N=3). These results further indicate that BCMA peptide encapsulation in nanoparticles, especially PLGA, effectively induce robust BCMA-specific CTL activities against tumor cells from HLA-A2 ${ }^{+}$myeloma patients.

\section{Increased BCMA-specific Tetramer+ CTL with CD28 upregulation in PLGA/peptide-CTL associated with BCMA peptide-specific Th1 cytokines production and proliferation}

To better characterize the anti-myeloma activities of BCMA-specific CTL, we evaluated the proportion of specific Tetramer ${ }^{+}$cells, CD28 costimulatory molecule expression and their immune functional activities in response to specific heteroclitic $\mathrm{BCMA}_{72-80}$ peptide stimulation. PLGA/peptide-CTL displayed induced CD28 upregulation (32\%) compared to free/peptide-CTL (16\%) within the gated CD8 ${ }^{+} \mathrm{T}$ cells and also showed a higher frequency (2.1 fold increase) of Tetramer ${ }^{+}$cells than the free peptide-CTL (Figure 5A, Lower panel). Furthermore, the BCMA-specific Tetramer ${ }^{+}$cells within the PLGA/peptide-CTL, not Tetramer- cells, showed an increased proportion of $\mathrm{CD} 28^{++}$bright cells (PLGA/peptideCTL: $52 \%$ vs. free peptide-CTL: 30\%). Next, both BCMA-CTL were evaluated for their proliferation and Th1-type cytokine production in response to specific heteroclitic BCMA $_{72-80}$ peptide stimulation. PLGA/peptide-CTL (25-69\%) consistently displayed a higher $\mathrm{CD}^{+} \mathrm{T}$ cell proliferation than free peptide CTL (11-33\%) in response to specific the BCMA peptide in a time-dependent manner (Figure 5B). In contrast, control $\mathrm{T}$ cells obtained upon stimulation with blank PLGA showed minimal proliferation $\left(\mathrm{CD}^{+}\right.$gated) in response to BCMA peptide on Day 3, 4 or 5 of culture $(0-4 \%)$. In addition, increased IFN$\gamma$ production was detected in the PLGA/peptide-CTL (34\% - 61\%) compared with free peptide-CTL (32\% - 42\%) and the difference continued to increase with longer stimulation with the specific heteroclitic BCMA $72-80$ peptide (Day 4 > Day 2) (Figure 5C). These results demonstrate enhanced BCMA-specific activities for PLGA/peptide-CTL than free peptideCTL as directly evidenced by increased Tetramer $^{+} \mathrm{CTL}$ and CD28 co-stimulatory signal expression, $\mathrm{CD} 8^{+} \mathrm{CTL}$ proliferation and IFN- $\gamma$ production.

\section{Enhanced myeloma-specific $\mathrm{CD}^{+} \mathrm{T}$ cell proliferation and memory cells development by stimulation with PLGA/peptide}

PLGA/peptide-CTL demonstrated a gradual increase in $\mathrm{CD}^{+} \mathrm{T}$ cell proliferation in response to HLA-A2 ${ }^{+}$U266 myeloma cells, which was higher than the proliferation of free peptide-CTL. Control PBMC stimulated with blank PLGA displayed minimal proliferation (Figure 6A), which confirms that PLGA itself is inert and can be used as a peptide delivery vehicle to induce antigen-specific CTL. The PLGA/peptide-CTL were further characterized for antigen-specific memory $\mathrm{T}$ cell development upon each round of stimulation. The development of $\mathrm{CD} 45 \mathrm{RO}^{+}$memory CTL occurred gradually after each round of heteroclitic $\mathrm{BCMA}_{72-80}$ peptide stimulation. In comparison, CTL generated with PLGA/peptide contained a higher proportion of $\mathrm{CD} 45 \mathrm{RO}^{+}$memory cells than free peptide-CTL as measured post 2 and 4 cycles of BCMA stimulation (Figure 6B; N=3) (Supplemental Fig. 4). Overall, the PLGA/peptide-CTL displayed higher frequencies of the central memory $\left(\mathrm{CM}: \mathrm{CCR}^{+} \mathrm{CD}^{2} 5 \mathrm{RO}^{+}\right.$) and effector memory (EM: CCR7 $\left.{ }^{-} \mathrm{CD} 45 \mathrm{RO}^{+}\right) \mathrm{CTL}$ subsets than 
free peptide-CTL. Of note, the PLGA/peptide-CTL also retained a higher proportion of CTL within the CM subset without further differentiation into EM after 5 cycles of stimulation (Figure 6C). These results provide additional evidence of the therapeutic potential of heteroclitic $\mathrm{BCMA}_{72-80}$ peptide encapsulated PLGA nanoparticles to effectively modulate antigen-specific memory CTL generation and maintenance with a high proportion of BCMA-specific central memory CTL subset.

\section{Robust anti-myeloma activity by BCMA-specific central memory CTL induced with PLGA/ peptide}

BCMA-specific CTL were further evaluated to identify the specific memory subsets having the highest immune functional activities against myeloma. The highest level of CD107a degranulation was consistently detected with the CM subset in PLGA/BCMA-CTL against HLA-A2 $2^{+}$myeloma cells (Figure 7A). Importantly, both CM and EM subsets of PLGA/ peptide-CTL demonstrated higher anti-tumor activity against HLA-A2 ${ }^{+} \mathrm{U} 266$ cells than the respective subsets from free peptide-CTL. Another key functional response assessed was Th1 cytokine production in response to myeloma. Consistent with degranulation, a higher level of IFN- $\gamma$ production was detected within the CM subset than the EM subset of the BCMA- CTL and the memory CTL activity was increased to a greater extent in the PLGA/ peptide-CTL (Figures 7B). Overall, the CM subset consistently displayed significantly ( ${ }^{*} p<$ 0.05) higher CD107a degranulation and Th1-type cytokine (IFN- $\gamma$, IL-2, TNF-a) production as compared to the EM subset in response to myeloma cells in an HLA-A2 restricted manner and the highest overall anti-MM activities were observed in the PLGA/ peptide-CTL (Figure 7C; $\mathrm{N}=3$ ). These results further demonstrate that heteroclitic BCMA $_{72-80}$ peptide encapsulated in PLGA nanoparticles induce a more robust myelomaspecific CTL than free BCMA peptide, as evidenced by their efficient induction and maintenance of highly functional memory CTL against myeloma.

\section{DISCUSSION}

Cancer vaccines targeting well-characterized TAA for treatment and prevention remain a highly innovative therapeutic approach with distinct advantages over other immunotherapies. This approach has the potential to induce long-lasting durable anti-tumor T cell immune responses and may overcome obstacles to widespread adoption of CAR-T therapy including high costs of complex ex vivo engineering and expansion, development of resistance through tumor-antigen loss, and lack of sustained memory CTL-specific anti-tumor activities. ${ }^{19,20}$ Unlike CAR-T therapy which provides a uniform non-renewable effector T cell pool, cancer vaccines induce a dynamic pool of effector and memory $\mathrm{T}$ cells that provide tumor-specific immunity through in vivo development of Th1-specific responses. ${ }^{21,22}$ In addition, unlike commonly used treatments or CAR-T therapy which can induce significant toxicities in patients, vaccines induce endogenous immune responses and TAA-specific memory function with few adverse events. ${ }^{23-25}$

With this rationale, we and others have developed methods to improve immune and clinical response to cancer vaccines. Specifically, we are continuously identifying TAA uniquely expressed on $\mathrm{CD} 138^{+}$tumor cells from newly diagnosed MM patients $(\mathrm{N}=1,254)$ and are 
developing protocols to target the novel antigens, as individually or as a multipeptide cocktail. To date, we have demonstrated the immunogenicity of XBP1, CD138 and CS1specific peptides and have shown that immunization with the XBP1, CD138 and CS1specific immunogenic peptides cocktail can induce myeloma-specific memory CTL having Th1 type immune responses in smoldering myeloma patients. ${ }^{7-10}$ Since then, we continue to develop clinical protocols to determine whether vaccination in combination with adjunct therapies, lenalidomide, checkpoint inhibitor, or histone deacetylase inhibitor can enhance the extent and durability of the vaccine-specific responses. Most recently, we reported on a novel immunogenic heteroclitic BCMA $72-80$ [YLMFLLRKI] peptide derived from human BCMA with enhanced HLA-A2 binding affinity, stability, and immunogenicity compared to the native $\mathrm{BCMA}_{72-80}$ [VLMFLLRKI] peptide. ${ }^{18}$ Importantly, the heteroclitic $\mathrm{BCMA}_{72-80}$ peptide induces robust BCMA-specific memory $\mathrm{CD}^{+} \mathrm{CTL}$ responses with anti-tumor activities and is being incorporated into a vaccine plus adoptive cellular immunotherapy in myeloma patients. In addition to identifying novel targets, we are also developing improved cancer vaccine delivery systems to facilitate uptake and suitable antigen release by dendritic cells to optimize the peptide presentation required for effective generation of antigenspecific CTL with poly-functional anti-MM activities. To that extent, we have exploited the remarkable progress in nanomedicines over the past decade to develop a potential delivery system. ${ }^{26-29}$ Specifically, advanced nanoparticles construct of polymeric micelles/vesicles or lipidic nanoparticles have enabled successful in vivo delivery of various small molecules, nucleic acids (mRNA, siRNA, DNA), and therapeutic proteins, for a biomedical and therapeutic applications. ${ }^{30-32}$ For example, nanoparticle-based therapies can augment tissuespecific drug delivery and promote controlled drug release due to increased surface area to drug volume ratios. ${ }^{33-36}$ Importantly, the therapeutic efficacy of nanoparticles-based therapy is highly dependent on the type of nanocarriers and their specific performance characteristics.

Here we report our findings using two different nanoparticles formulations encapsulating

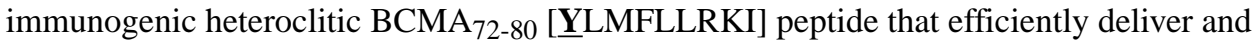
induce myeloma-specific CD8 ${ }^{+}$CTL. Our chosen PLGA- and lipid-based nanoparticle delivery constructs have previously shown in vivo compatibility and biodegradability and are approved for human usage by the US Food and Drug Administration (FDA), making them ideal for clinical application. ${ }^{37-41}$ In these studies, we specifically demonstrate improved efficiency for encapsulated PLGA or liposome nanoparticles to deliver our immunogenic BCMA peptide to human dendritic cells, as compared to free peptide alone. Both nanoparticle constructs exhibit uniform size distribution, had similar efficiency of BCMA peptide encapsulation and provide improved peptide delivery to dendritic cells. Interestingly, the kinetics of peptide loading to dendritic cells and subsequent induction of BCMA-specific $\mathrm{CD}^{+} \mathrm{CTL}$ were distinct between the two formulations; PLGA/peptide required a longer period of time (18 hours) for maximum peptide loading, while liposome-nanoparticles/ peptide achieved the maximum loading in just 30 minutes. Distinct from the loading kinetics, the PLGA/peptide induced a more effective BCMA-specific CTL characterized by their robust poly-functional anti-myeloma activities (CD107a degranulation-based cytotoxicity and Th1-type cytokine production) than the liposome/peptide. Based on these observations, we hypothesize that "gradual" antigen uptake and delivery of immunogenic 
peptide by dendritic cells to naïve $\mathrm{CD} 8^{+} \mathrm{T}$ cells will result in a more efficient induction of the antigen-specific CTL with a greater level of anti-tumor activities. Other investigators have reported that nanoparticles-based cancer vaccines evoke both humoral and cellular Tcell responses ${ }^{42-44}$, but these nanoparticle-based cancer vaccines have not achieved prolonged extent and duration of ant-tumor responses in patients and have not shown clinical benefit to date. However, it is important to note that the clinical trials evaluated nanoparticlebased cancer vaccines utilized mainly lipid or liposome as the nano-vehicle. ${ }^{45-48}$ In comparison, PLGA-based nanoparticles have been evaluated as delivery vehicles for therapy, mainly in preclinical models, for diseases such as hepatitis B, chlamydia, malaria, leishmaniasis, tuberculosis, toxoplasmosis; they have shown an excellent safety profile and biodegradability as a controlled-release system, ${ }^{49-54}$ providing further rationale for their clinical development in cancer therapies. Here, we demonstrate encouraging results using PLGA as a delivery system and propose BCMA peptide encapsulated PLGA-nanoparticles as an effective strategy to improve the peptide delivery to antigen-presenting cells and the subsequent enhancement in the development of BCMA-specific CTL with robust antimyeloma activities. Additionally, the results presented here collaborates prior reports showing that PLGA as a carrier confers protection of loaded antigen against proteolytic degradation, prolongs plasma half-life and promotes long-term antigen release ${ }^{55-56}$ and is an effective delivery vehicle for induction of effective and long-lasting immunity, thereby potentially avoiding or reducing the multiple administrations required in conventional vaccine approaches. ${ }^{57-60}$

In summary, we report on novel immunogenic heteroclitic $\mathrm{BCMA}_{72-80}$ peptide encapsulated nanoparticle delivery systems that promote generation and maintenance of highly functional myeloma-specific CTL. Based on these results presented here, we propose to use PLGA nanoparticles as the optimal delivery system for heteroclitic $\mathrm{BCMA}_{72-80}$ peptide. These studies provide the rationale for immunotherapeutic strategies and framework for nanomedicine-based cancer vaccine and adoptive cellular therapy in which PLGA-based peptide vaccination induces antigen-specific memory CTL in vivo, which are then harvested, expanded ex vivo in the presence of peptide and re-infused to patients; nanoparticle-based cancer vaccination can then be used as needed to maintain the memory CTL activities against myeloma.

\title{
Supplementary Material
}

Refer to Web version on PubMed Central for supplementary material.

\section{ACKNOWLEDGEMENT}

\author{
The authors acknowledge the Miriam and Sheldon G Adelson Medical Research Foundation. This work was also \\ supported in part by grants from the National Institutes of Health Grants Special Program in Oncology Research \\ Excellence (SPORE) P50 100707, RO1 CA 207237, and RO1 CA 050947. Dr. Kenneth C. Anderson is an \\ American Cancer Society Clinical Research Professor. \\ Financial support, including the source and number of grants, for each author: \\ NIH Special Program in Oncology Research Excellence (SPORE) P50 100707, RO1 CA 207237, and RO1 CA \\ 050947.
}




\section{REFERENCES}

1. Miliotou AN, Papadopoulou LC. CAR T-cell Therapy: A New Era in Cancer Immunotherapy. Curr Pharm Biotechnol 2018; 19: 5-18. [PubMed: 29667553]

2. Legut M, Sewell AK. Designer T-cells and T-cell receptors for customized cancer immunotherapies. Curr Opin Pharmacol 2018; 41: 96-103. [PubMed: 29852403]

3. Ping Y, Liu C, Zhang Y. T-cell receptor-engineered T cells for cancer treatment: current status and future directions. Protein Cell 2018; 9: 254-266. [PubMed: 28108950]

4. Salter AI, Pont MJ, Riddell SR. Chimeric antigen receptor-modified T cells: CD19 and the road beyond. Blood 2018; 131: 2621-2629. [PubMed: 29728402]

5. Curran MA, Glisson BS. New Hope for Therapeutic Cancer Vaccines in the Era of Immune Checkpoint Modulation. Annu Rev Med 2018; doi:10.1146/annurev-med-050217-121900.

6. Chamani R, Ranji P, Hadji M, Nahvijou A, Esmati E, Alizadeh AM. Application of E75 peptide vaccine in breast cancer patients: A systematic review and meta-analysis. Eur J Pharmacol 2018; 831: 87-93. [PubMed: 29753042]

7. Bae J, Carrasco R, Lee AH, Prabhala R, Tai YT, Anderson KC et al. Identification of novel myeloma-specific XBP1 peptides able to generate cytotoxic T lymphocytes: a potential therapeutic application in multiple myeloma. Leukemia 2011; 25: 1610-1619. [PubMed: 21660045]

8. Bae J, Tai YT, Anderson KC, Munshi NC. Novel epitope evoking CD138 antigen-specific cytotoxic T lymphocytes targeting multiple myeloma and other plasma cell disorders. Br J Haematol 2011; 155: 349-361. [PubMed: 21902685]

9. Bae J, Song W, Smith R, Daley J, Tai YT, Anderson KC et al. A novel immunogenic CS1-specific peptide inducing antigen-specific cytotoxic T lymphocytes targeting multiple myeloma. $\mathrm{Br} \mathrm{J}$ Haematol 2012; 157: 687-701. [PubMed: 22533610]

10. Nooka AJ, Wang M, Yee AJ, Kaufman J, Bae J, Peterkin D et al. Safety and Immunogenicity of PVX-410 Vaccine \pm lenalidomide in smoldering multiple myeloma. JAMA Oncology 2018; 8 16:e183267.

11. Tran T, Blanc C, Granier C, Saldmann A, Tanchot C, Tartour E. Therapeutic cancer vaccine: building the future from lessons of the past. Semin Immunopathol 2018; doi:10.1007/ s00281-018-0691-z.

12. Scharping NE, Delgoffe GM. Tumor Microenvironment Metabolism: A New Checkpoint for AntiTumor Immunity. Vaccines (Basel) 2016; 4.pii:E46. [PubMed: 27929420]

13. Strauss J, Madan RA, Gulley JL. Considerations for the combination of anticancer vaccines and immune checkpoint inhibitors. Expert Opin Biol Ther 2016; 16: 895-901. [PubMed: 27010190]

14. Moreaux J, Legouffe E, Jourdan E, Quittet P, Rème T, Lugagne C et al. BAFF and APRIL protect myeloma cells from apoptosis induced by interleukin 6 deprivation and dexamethasone. Blood 2004; 103: 3148-3157. [PubMed: 15070697]

15. O'Connor BP, Raman VS, Erickson LD, Cook WJ, Weaver LK, Ahonen C et al. BCMA is essential for the survival of long-lived bone marrow plasma cells. J Exp Med 2004; 199: 91-98. [PubMed: 14707116]

16. Coquery CM, Erickson LD. Regulatory roles of the tumor necrosis factor receptor BCMA. Crit Rev Immunol 2012; 32: 287-305. [PubMed: 23237506]

17. Bae J, Samur M, Richardson P, Munshi NC, Anderson KC. Selective Targeting of Multiple Myeloma by B cell Maturation Antigen (BCMA)-specific Central Memory CD8 ${ }^{+}$Cytotoxic T Lymphocytes: Immunotherapeutic Application in Vaccination and Adoptive Immunotherapy. Leukemia 2018; Manuscript Accepted.

18. Sahoo SK, Ma W, Labhasetwar V. Efficacy of transferrin-conjugated paclitaxel-loaded nanoparticles in a murine model of prostate cancer. Int J Cancer 2004; 112: 335-340. [PubMed: 15352049]

19. Brudno JN, Kochenderfer JN. Chimeric antigen receptor T-cell therapies for lymphoma. Nat Rev Clin Oncol 2018; 15: 31-46. [PubMed: 28857075]

20. O'Rourke DM, Nasrallah MP, Desai A, Melenhorst JJ, Mansfield K, Morrissette JD et al. A single dose of peripherally infused EGFRvIII-directed CAR T cells mediates antigen loss and induces 
adaptive resistance in patients with recurrent glioblastoma. Sci Transl Med 2017; 9.pii:eaaa0984. [PubMed: 28724573]

21. Parvizpour Sepideh, Razmara Jafar, Omidi Yadollah. Breast cancer vaccination comes to age: impacts of bioinformatics. Bioimpacts 2018; 8: 223-235. [PubMed: 30211082]

22. Chiang CL, Kandalaft LE, Tanyi J, Hagemann AR, Motz GT, Svoronos N et al. A dendritic cell vaccine pulsed with autologous hypochlorous acid-oxidized ovarian cancer lysate primes effective broad antitumor immunity: from bench to bedside. Clin Cancer Res 2013; 19: 4801-4815. [PubMed: 23838316]

23. Neelapu SS, Tummala S, Kebriaei P, Wierda W, Gutierrez C, Locke FL et al. Chimeric antigen receptor T-cell therapy - assessment and management of toxicities. Nat Rev Clin Oncol 2018; 15: 47-62. [PubMed: 28925994]

24. Kenderian SS, Porter DL, Gill S. Chimeric Antigen Receptor T Cells and Hematopoietic Cell Transplantation: How Not to Put the CART Before the Horse. Biol Blood Marrow Transplant 2017; 23: 235-246. [PubMed: 27638367]

25. Schwarzbich MA, Witzens-Harig M. Cellular Immunotherapy in B-Cell Malignancy. Oncol Res Treat 2017; 40: 674-681. [PubMed: 29065420]

26. Buddolla AL, Kim S. Recent insights into the development of nucleic acid-based nanoparticless for tumor-targeted drug delivery. Colloids Surf B Biointerfaces 2018; 172: 315-322. [PubMed: 30176511]

27. Deshantri AK, Varela Moreira A, Ecker V, Mandhane SN, Schiffelers RM, Buchner M et al. Nanomedicines for the treatment of hematological malignancies. J Control Release 2018; 287: 194-215. [PubMed: 30165140]

28. Iqbal J, Abbasi BA, Ahmad R, Mahmood T, Ali B, Khalil AT et al. Nanomedicines for developing cancer nanotherapeutics: from benchtop to bedside and beyond. Appl Microbiol Biotechnol 2018; 102: 9449-9470. [PubMed: 30219952]

29. Tabassum N, Verma V, Kumar M, Kumar A, Singh B. Nanomedicine in cancer stem cell therapy: from fringe to forefront. Cell Tissue Res 2018; doi:10.1007/s00441-018-2928-5.

30. Zhang Y, Zhang P, Zhu T. Ovarian carcinoma biological nanotherapy: Comparison of the advantages and drawbacks of lipid, polymeric, and hybrid nanoparticles for cisplatin delivery. Biomed Pharmacother 2018; 109: 475-483. [PubMed: 30399584]

31. Desfrançois C, Auzély R, Texier I. Lipid Nanoparticles and Their Hydrogel Composites for Drug Delivery: A Review. Pharmaceuticals (Basel) 2018; 11.pii:E118.doi:10.3390/ph11040118. [PubMed: 30388738]

32. Hong SJ, Ahn MH, Lee YW, Pal S, Sangshetti J, Arote RB. Biodegradable Polymeric NanocarrierBased Immunotherapy in Hepatitis Vaccination. Adv Exp Med Biol 2018; 1078: 303-320. [PubMed: 30357630]

33. Aftab S, Shah A, Nadhman A, Kurbanoglu S, Aysil Ozkan S, Dionysiou DD et al. Nanomedicine: An effective tool in cancer therapy. Int J Pharm 2018; 540: 132-149. [PubMed: 29427746]

34. Aw MS, Paniwnyk L. Overcoming T. gondii infection and intracellular protein nanocapsules as biomaterials for ultrasonically controlled drug release. Biomater Sci 2017; 5: 1944-1961. [PubMed: 28776612]

35. Bayford R, Rademacher T, Roitt I, Wang SX. Emerging applications of nanotechnology for diagnosis and therapy of disease: a review. Physiol Meas 2017; 38: R183-R203. [PubMed: 28480874]

36. Tang Q, Yu B, Gao L, Cong H, Song N, Lu C. Stimuli Responsive Nanoparticles for Controlled Anti-cancer Drug Release. Curr Med Chem 2018; 25: 1837-1866. [PubMed: 29332566]

37. Jahan ST, Sadat SM, Haddadi A. Design and immunological evaluation of anti-CD205-tailored PLGA-based nanoparticulate cancer vaccine. Int J Nanomedicine 2018; 13: 367-386. [PubMed: 29391795]

38. Kim H, Niu L, Larson P, Kucaba TA, Murphy KA, James BR et al. Polymeric nanoparticles encapsulating novel TLR7/8 agonists as immunostimulatory adjuvants for enhanced cancer immunotherapy. Biomaterials 2018; 164: 38-53. [PubMed: 29482062]

39. Wang D, Sun Y, Liu Y, Meng F, Lee RJ. Clinical translation of immunoliposomes for cancer therapy: recent perspectives. Expert Opin Drug Deliv 2018; 15: 893-903. [PubMed: 30169978] 
40. Graziani SR, Vital CG, Morikawa AT, Van Eyll BM, Fernandes Junior HJ, Kalil Filho R et al. Phase II study of paclitaxel associated with lipid core nanoparticles (LDE) as third-line treatment of patients with epithelial ovarian carcinoma. Med Oncol 2017; 34: 151. [PubMed: 28756613]

41. Grabbe S, Haas H, Diken M, Kranz LM, Langguth P, Sahin U. Translating nanoparticulatepersonalized cancer vaccines into clinical applications: case study with RNA-lipoplexes for the treatment of melanoma. Nanomedicine (Lond) 2016; 11: 2723-2734. [PubMed: 27700619]

42. Butts C, Socinski MA, Mitchell PL, Thatcher N, Havel L, Krzakowski M et al. Tecemotide (LBLP25) versus placebo after chemoradiotherapy for stage III non-small-cell lung cancer (START): a randomized, double-blind, phase 3 trial. Lancet Oncol 2014; 15: 59-68. [PubMed: 24331154]

43. Vansteenkiste JF, Vanakesa T, De Pas T, Zielinski M, Kim MS, Jassem J et al. MAGRIT, a doubleblind, randomized, placebo-controlled Phase III study to assess the efficacy of the RecMAGE-A3 + AS15 cancer immunotherapeutic as adjuvant therapy in patients with resected MAGE-A3Positive non-small cell lung cancer (NSCLC). Ann Oncol 2014; 25: 409-416. [PubMed: 24368400]

44. Kruit WHJ, Suciu S, Dreno B, Mortier L, Robert C, Chiarion-Sileni V et al. Selection of immunostimulant AS15 for active immunization with MAGE-A3 protein: results of a randomized phase II study of the European Organization for Research and Treatment of Cancer Melanoma Group in Metastatic Melanoma. J Clin Oncol 2013; 31: 2413-2420. [PubMed: 23715572]

45. Vansteenkiste JF, Cho BC, Vanakesa T, De Pas T, Zielinski M, Kim MS et al. Efficacy of the MAGE-A3 cancer immunotherapeutic as adjuvant therapy in patients with resected MAGE-A3positive non-small-cell lung cancer (MAGRIT): a randomized, double-blind, placebo-controlled, phase 3 trial. Lancet Oncol 2016; 17: 822-835. [PubMed: 27132212]

46. Limentani SA, Campone M, Dorval T, Curigliano G, de Boer R, Vogel C et al. A non-randomized dose-escalation Phase I trial of a protein-based immunotherapeutic for the treatment of breast cancer patients with HER2-overexpressing tumors. Breast Cancer Res Treat 2016; 156: 319-330. [PubMed: 26993131]

47. Berinstein NL, Karkada M, Oza AM, Odunsi K, Villella JA, Nemunai- tis JJ et al. Survivintargeted immunotherapy drives robust polyfunctional $\mathrm{T}$ cell generation and differentiation in advanced ovarian cancer patients. Oncoimmunology 2015; 4: e1026529. [PubMed: 26405584]

48. Saito T, Wada H, Yamasaki M, Miyata H, Nishikawa H, Sato E et al. High expression of MAGEA4 and MHC class I antigens in tumor cells and induction of MAGE-A4 immune responses are prognostic markers of CHP-MAGE-A4 cancer vaccine. Vaccine 2014; 32: 5901-5907. [PubMed: 25218300]

49. Bavananthasivam J, Alkie TN, Astill J, Abdul-Careem MF, Wootton SK, Behboudi S et al. In ovo administration of Toll-like receptor ligands encapsulated in PLGA nanoparticles impede tumor development in chickens infected with Marek's disease virus. Vaccine 2018; 36: 4070-4076. [PubMed: 29859800]

50. Thompson EA, Ols S, Miura K, Rausch K, Narum DL, Spångberg M et al. TLR-adjuvanted nanoparticles vaccines differentially influence the quality and longevity of responses to malaria antigen Pfs25. JCI Insight 2018; 3.pii:120692. [PubMed: 29769448]

51. Zupančič E, Curato C, Paisana M, Rodrigues C, Porat Z, Viana AS et al. Rational design of nanoparticles towards targeting antigen-presenting cells and improved $\mathrm{T}$ cell priming. J Control Release 2017; 258: 182-195. [PubMed: 28511928]

52. Salvador A, Igartua M, Hernandez RM, Pedraz JL. Combination of immune stimulating adjuvants with poly(lactide-co-glycolide) microspheres enhances the immune response of vaccines. Vaccine 2012; 30: 589-596. [PubMed: 22119926]

53. Lee YR, Lee YH, Im SA, Kim K, Lee CK. Formulation and Characterization of Antigen-loaded PLGA Nanoparticles for Efficient Cross-priming of the Antigen. Immune Netw 2011; 11: 163168. [PubMed: 21860609]

54. Kasturi SP, Skountzou I, Albrecht RA, Koutsonanos D, Hua T, Nakaya HI et al. Programming the magnitude and persistence of antibody responses with innate immunity. Nature 2011; 470: 543547. [PubMed: 21350488]

55. Allahyari M, Mohit E. Peptide/protein vaccine delivery system based on PLGA particles. Hum Vaccin Immunother 2016; 12: 806-828. [PubMed: 26513024] 
56. Silva AL, Rosalia RA, Varypataki E, Sibuea S, Ossendorp F, Jiskoot W Poly-(lactic-co-glycolicacid)-based particulate vaccines: particle uptake by dendritic cells is a key parameter for immune activation. Vaccine 2015; 33: 847-854. [PubMed: 25576216]

57. Saini V, Jain V, Sudheesh MS, Jaganathan KS, Murthy PK, Kohli DV. Comparison of humoral and cell-mediated immune responses to cationic PLGA microspheres containing recombinant hepatitis B antigen. Int J Pharm 2011; 408: 50-57. [PubMed: 21291968]

58. Feng L, Qi XR, Zhou XJ, Maitani Y, Wang SC, Jiang Y et al. Pharmaceutical and immunological evaluation of a single-dose hepatitis B vaccine using PLGA microspheres. J Controlled Release 2006; 112: 35-42.

59. Jaganathan KS, Singh P, Prabakaran D, Mishra V, Vyas SP. Development of a single-dose stabilized poly(D,L-lactic-co-glycolic acid) microspheres-based vaccine against hepatitis B. J Pharm Pharmacol 2004; 56: 1243-1250. [PubMed: 15482638]

60. Rosas JE, Pedraz JL, Hernandez RM, Gascon AR, Igartua M, Guz- man F et al. Remarkably high antibody levels and protection against P. falciparum malaria in Aotus monkeys after a single immunisation of SPf66 encapsulated in PLGA microspheres. Vaccine 2002; 20: 1707-1710. [PubMed: 11906756] 


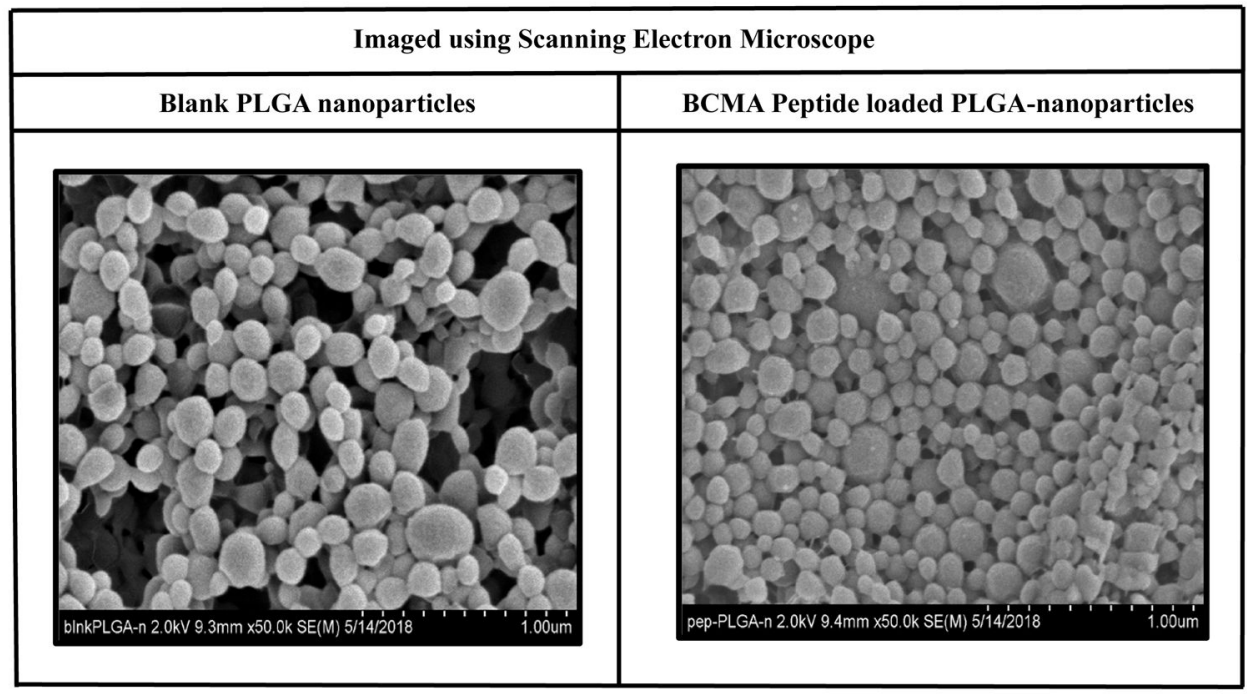

\begin{tabular}{|c|c|c|c|c|}
\hline & Formulation & $\begin{array}{c}\text { Size }(\mathbf{d} . n m) \\
(\mathbf{N}=\mathbf{3})\end{array}$ & $\begin{array}{c}\text { PDI } \\
(\mathbf{N}=\mathbf{3})\end{array}$ & $\begin{array}{c}\text { Zeta Potential }(\mathbf{m V}) \\
(\mathbf{N}=\mathbf{3})\end{array}$ \\
\hline $\mathbf{1}$ & Blank PLGA-nanoparticles & $\mathbf{3 0 9} \pm \mathbf{4 . 0 1}$ & $\mathbf{0 . 1 4} \pm \mathbf{0 . 0 3}$ & $\mathbf{- 0 . 6 6} \pm \mathbf{0 . 2 5}$ \\
\hline $\mathbf{2}$ & $\begin{array}{c}\text { BCMA Peptide loaded } \\
\text { PLGA-nanoparticles }\end{array}$ & $\mathbf{2 5 7} \pm \mathbf{1 1 . 5 3}$ & $\mathbf{0 . 1 3} \pm \mathbf{0 . 0 1}$ & $\mathbf{- 1 . 1 6 \pm 0 . 1 8}$ \\
\hline
\end{tabular}


Imaged using Transmission Electron Microscope

BCMA Peptide loaded

Liposome-nanoparticles

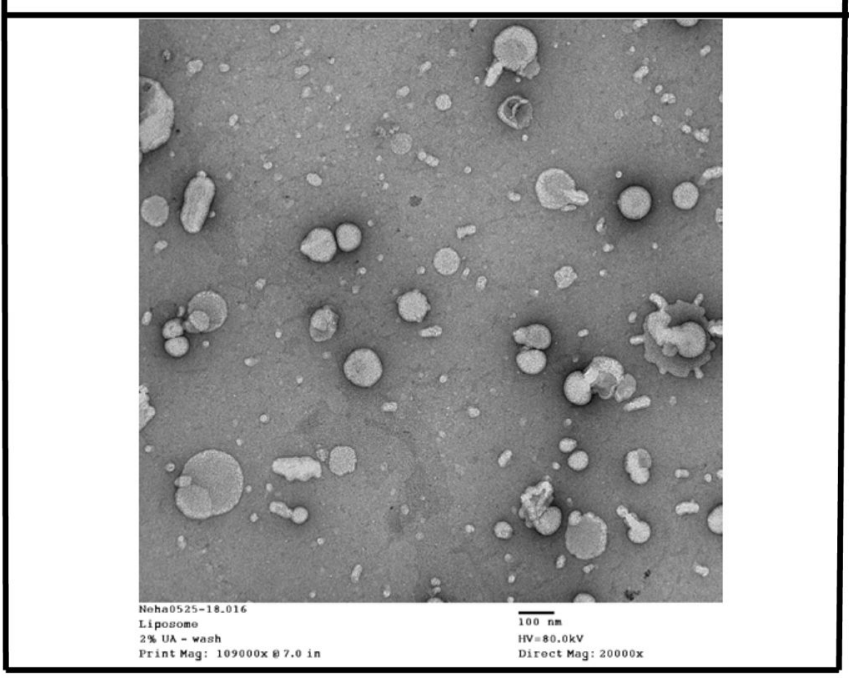

\begin{tabular}{|c|c|c|}
\hline Formulation & $\begin{array}{c}\text { Size }(\text { d.nm }) \\
(\mathbf{N}=\mathbf{3})\end{array}$ & $\begin{array}{c}\text { PDI } \\
(\mathbf{N}=\mathbf{3})\end{array}$ \\
\hline $\begin{array}{c}\text { BCMA Peptide loaded } \\
\text { Liposome-nanoparticles }\end{array}$ & $\mathbf{1 7 2} \pm \mathbf{0 . 7 3}$ & $\mathbf{0 . 2 0} \pm \mathbf{0 . 0 1}$ \\
\hline
\end{tabular}




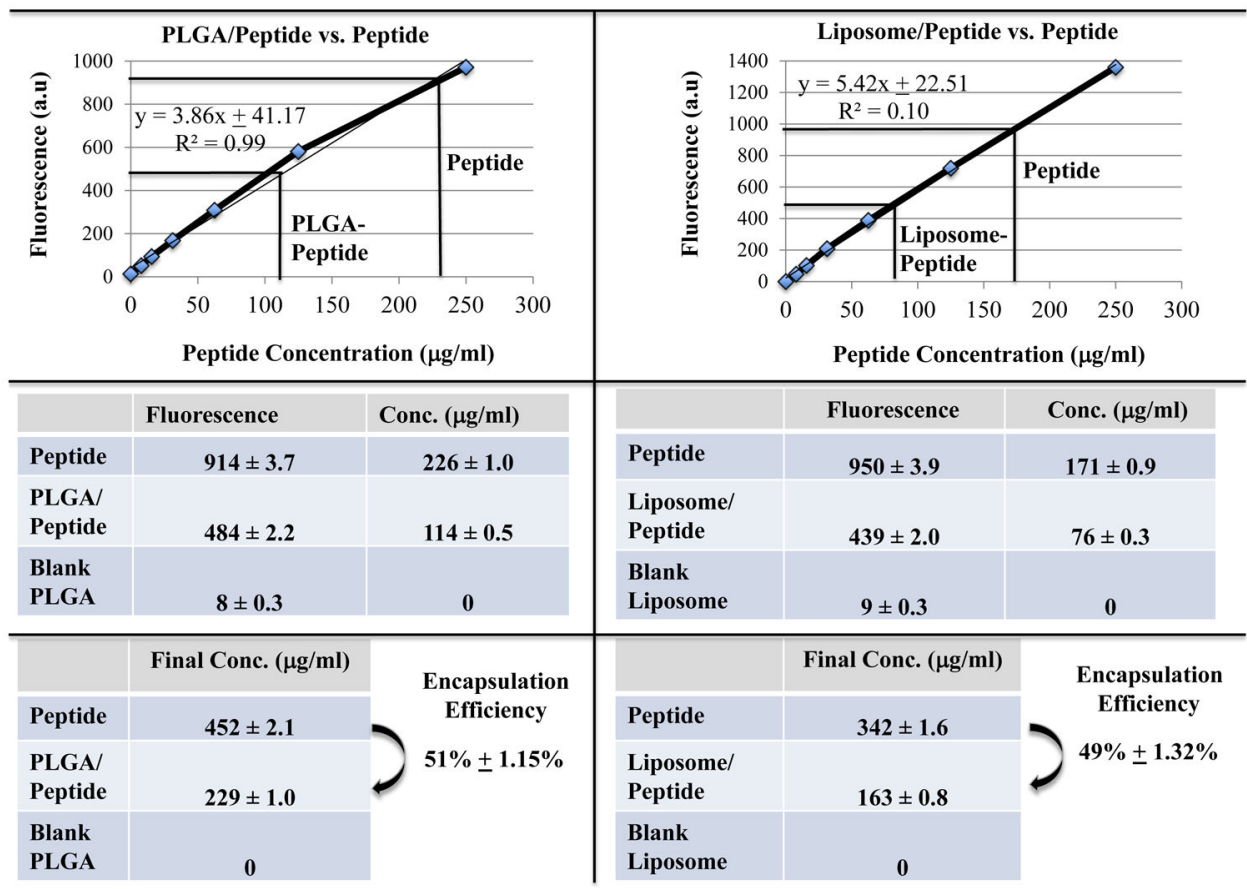

Figure 1. Morphology of heteroclitic BCMA72-80 peptide-encapsulated nanoparticles (PLGA, liposome) and quantification of $\mathrm{BCMA}_{72-80}$ peptide encapsulation.

A: Scanning electron microscope (SEM) image of gold/palladium sputter-coated BCMA peptide encapsulated PLGA-nanoparticles. Summary of nanoparticle size, PDI and Zeta potential $(\mathrm{mV})$ from three independent experiments $(\mathrm{N}=3)$. B: Transmission electron microscope (TEM) image of BCMA peptide encapsulated liposome-nanoparticles after applying uranyl acetate as a negative stain. Summary of nanoparticle size and PDI from three independent experiments $(\mathrm{N}=3)$. C: Quantification of BCMA peptide-FITC loading and encapsulation efficiency based on fluorescence intensity measured at Ex/Em at 390 $\mathrm{nm} / 475 \mathrm{~nm}$. Summary of the average of encapsulation efficiency from three independent experiments $(\mathrm{N}=3)$. 


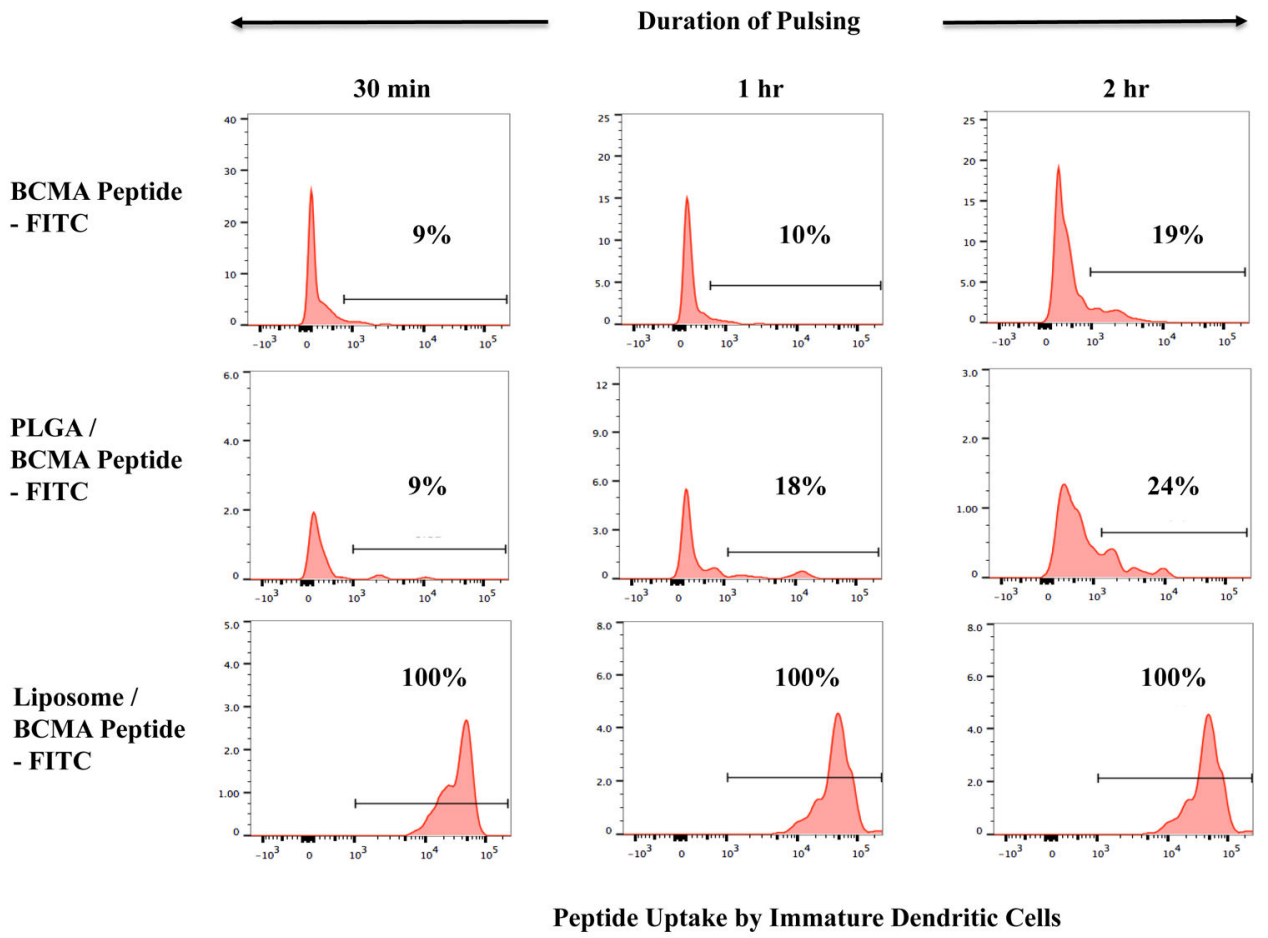

Peptide Uptake by Immature Dendritic Cells $(\mathrm{N}=\mathbf{3})$

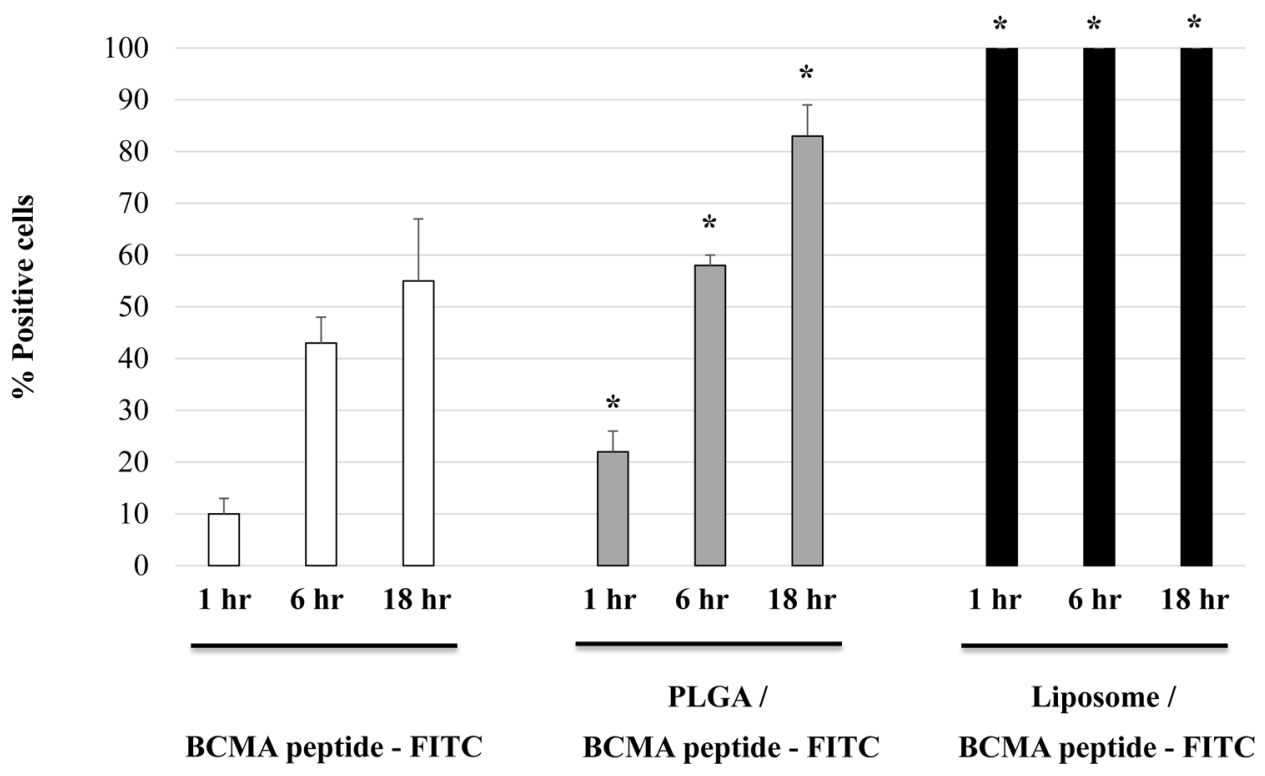

Leukemia. Author manuscript; available in PMC 2020 July 01. 


\section{Red - Dendritic Cells $\quad$ Green - BCMA peptide-FITC}

Dendritic cells

(no peptide pulsing)

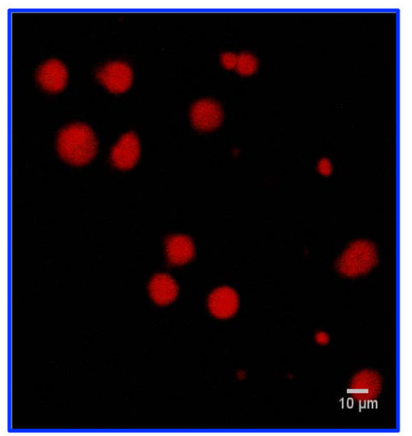

Dendritic cells pulsed with BCMA peptide-FITC

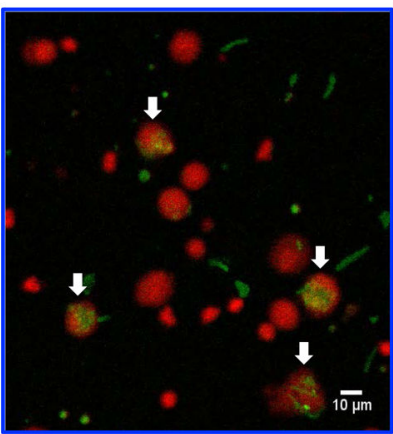

Dendritic cells pulsed with PLGA / BCMA Peptide-FITC

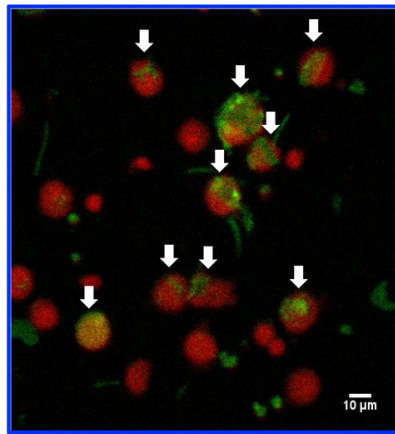

Figure 2. Enhanced loading efficiency of heteroclitic BCMA $\mathbf{B 2}_{\mathbf{7 2}}$ peptide encapsulated nanoparticles by immature dendritic cells.

A: Representative flow cytometric analyses of time-dependent (0.5 - 2 hours) uptake of BCMA peptide-FITC by immature dendritic cells, as (1) free peptide, (2) encapsulated in PLGA, or (3) encapsulated in liposome. B: A summary of three independent flow cytometric analyses $(\mathrm{N}=3)$, showing time-dependent (1 - 18 hours) uptake of BCMA peptide-FITC by immature dendritic cells, as (1) free peptide, (2) encapsulated in PLGA, or (3) encapsulated in liposome. C: Representative confocal microscopic analyses of (1) immature dendritic cells alone (no peptide pulsed), (2) immature dendritic cells pulsed with BCMA peptide-FITC, or (3) immature dendritic cells pulsed with BCMA peptide-FITC encapsulated PLGA nanoparticles after pulsing for 18 hours. 


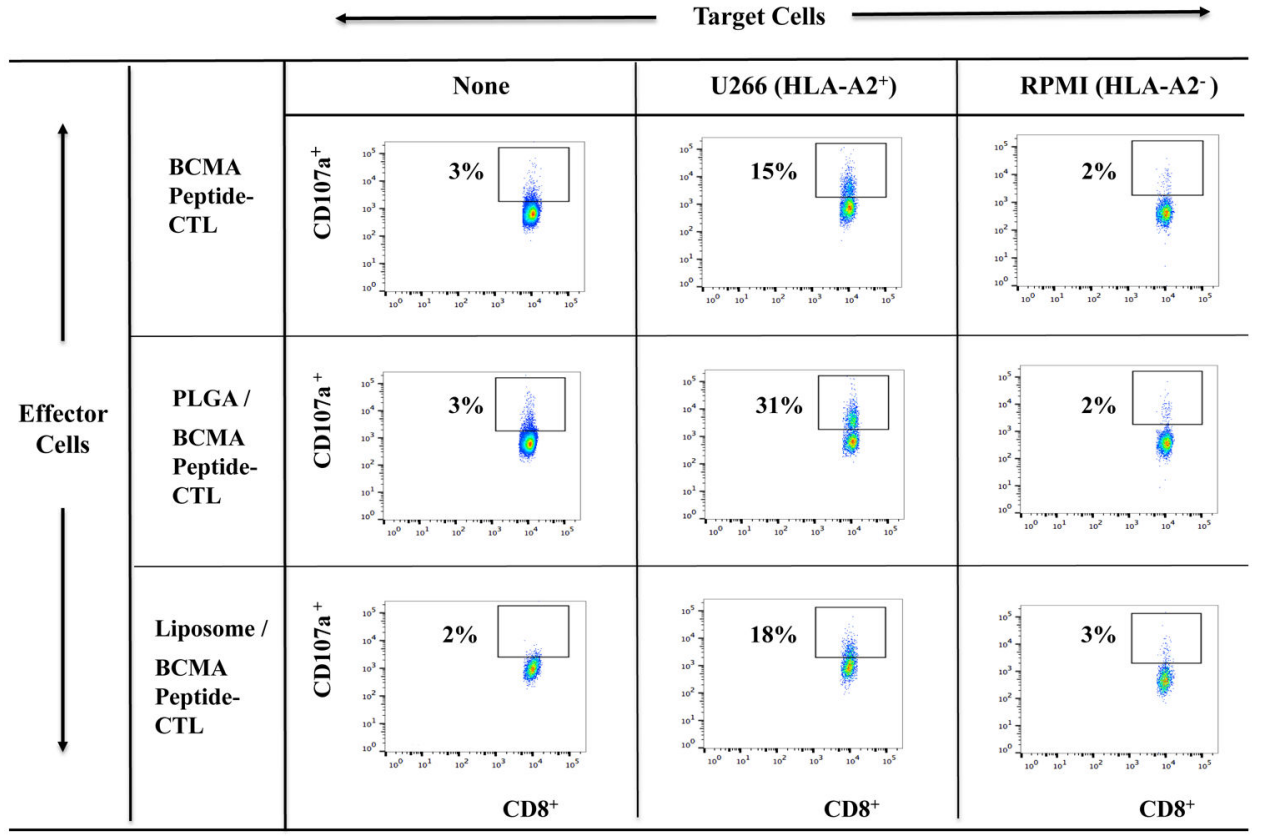

Target Cells

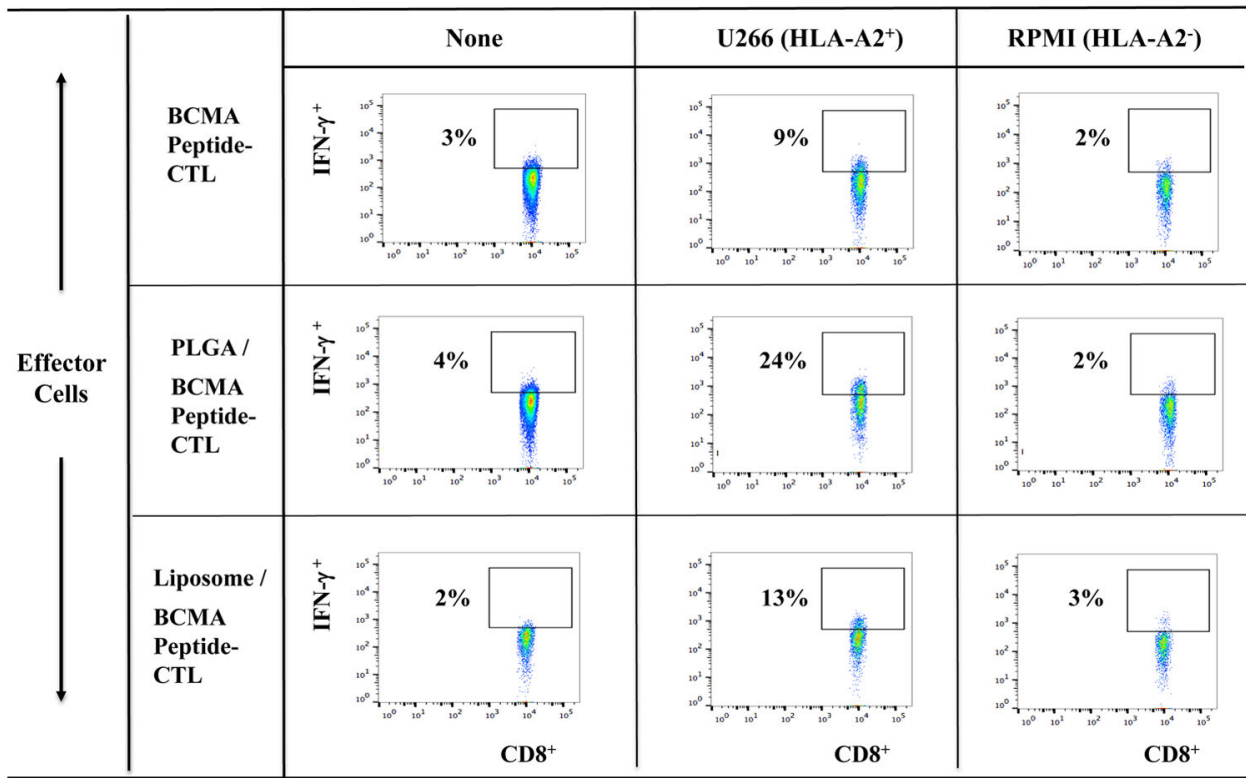

Leukemia. Author manuscript; available in PMC 2020 July 01. 


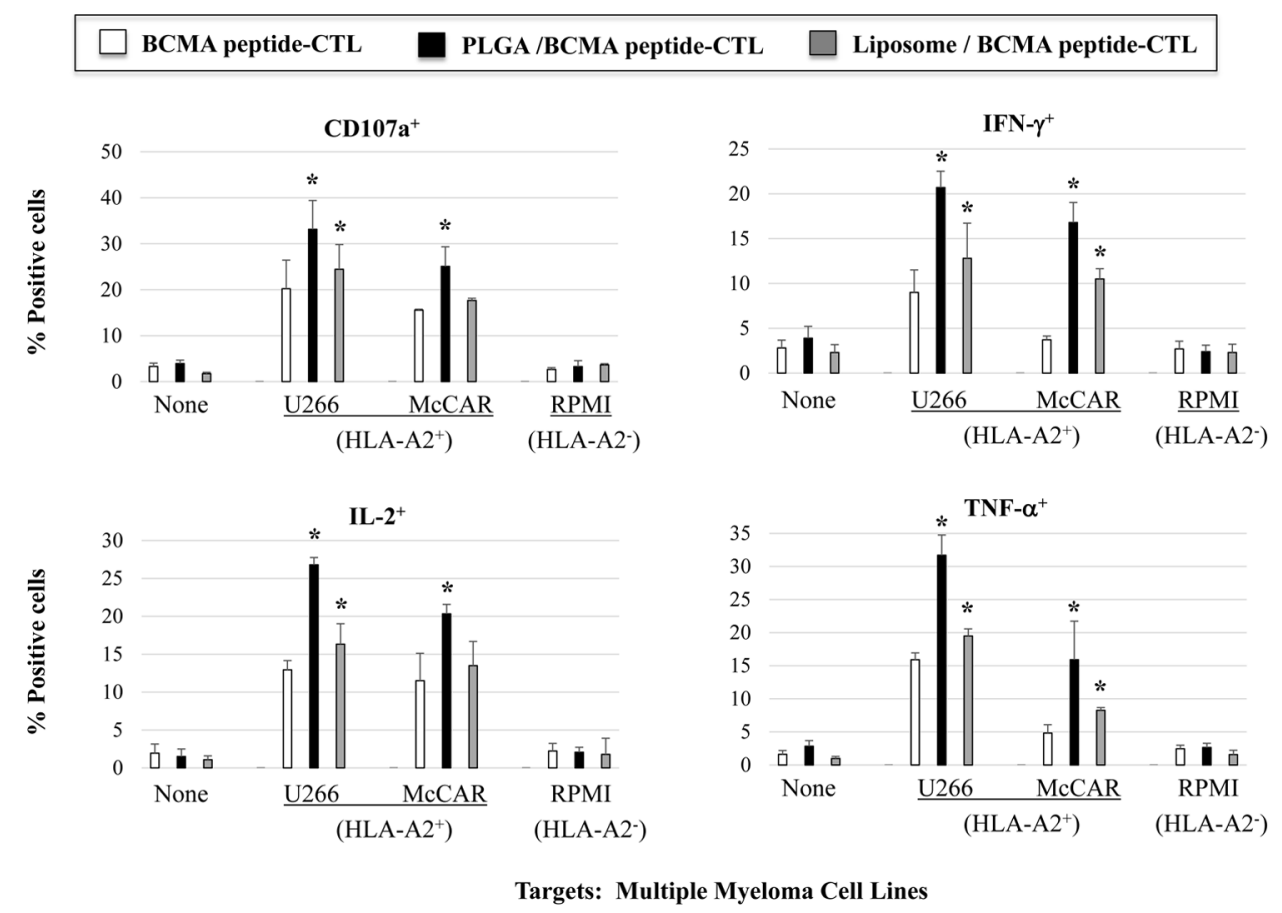

Figure 3. Increased immune responses of BCMA-specific CTL induced with BCMA peptideencapsulated nanoparticles against multiple myeloma cell lines.

HLA-A2-restrcited anti-myeloma activities of heteroclitic BCMA-specific CTL generated from HLA-A2 ${ }^{+}$normal donor's PBMC by stimulation with (1) free peptide, (2) PLGA/ peptide or (3) liposome/peptide. Functional immune activities were assessed by (A) CD107a degranulation, (B) IFN- $\gamma$ production, (C) IL-2 production, and (D) TNF-a production. 


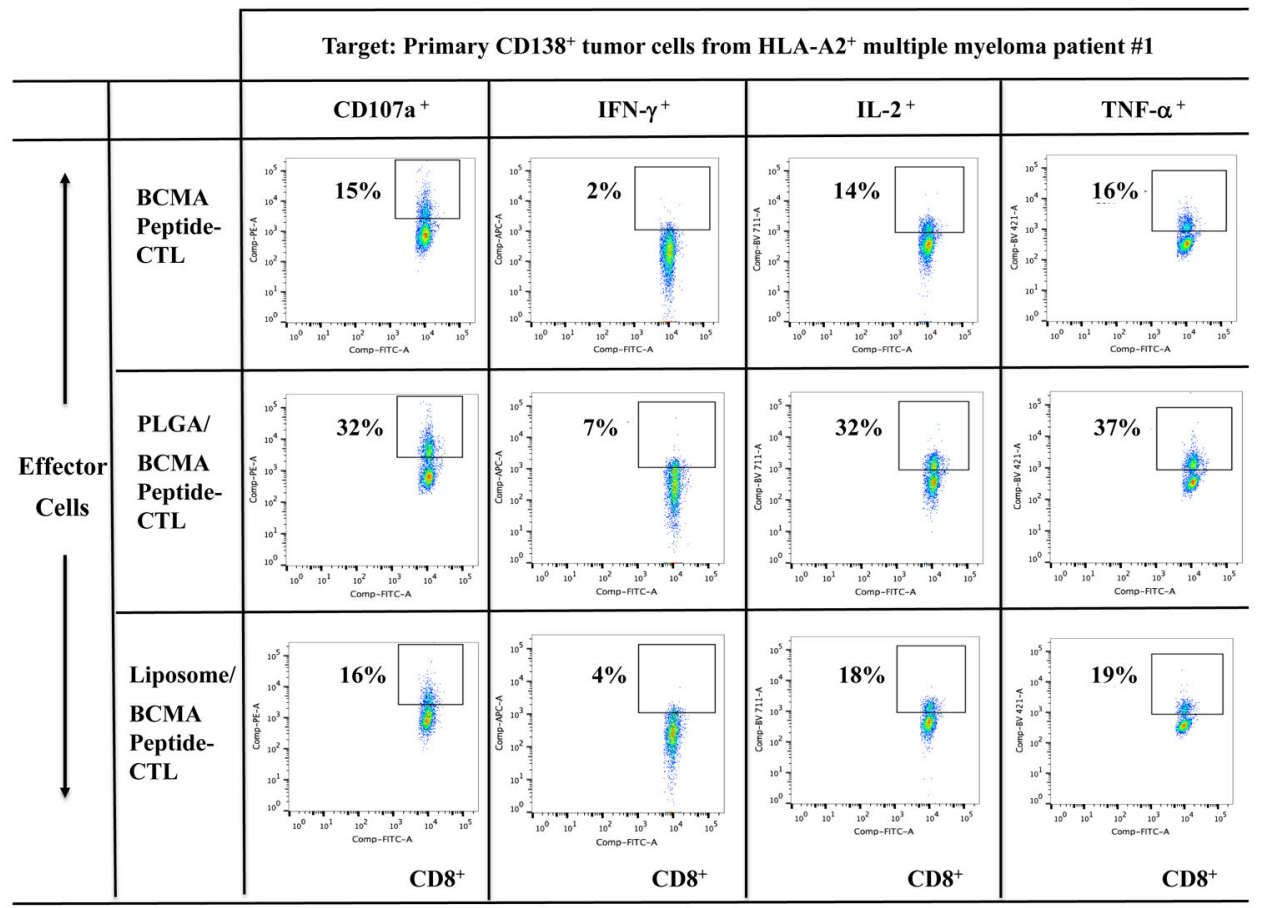

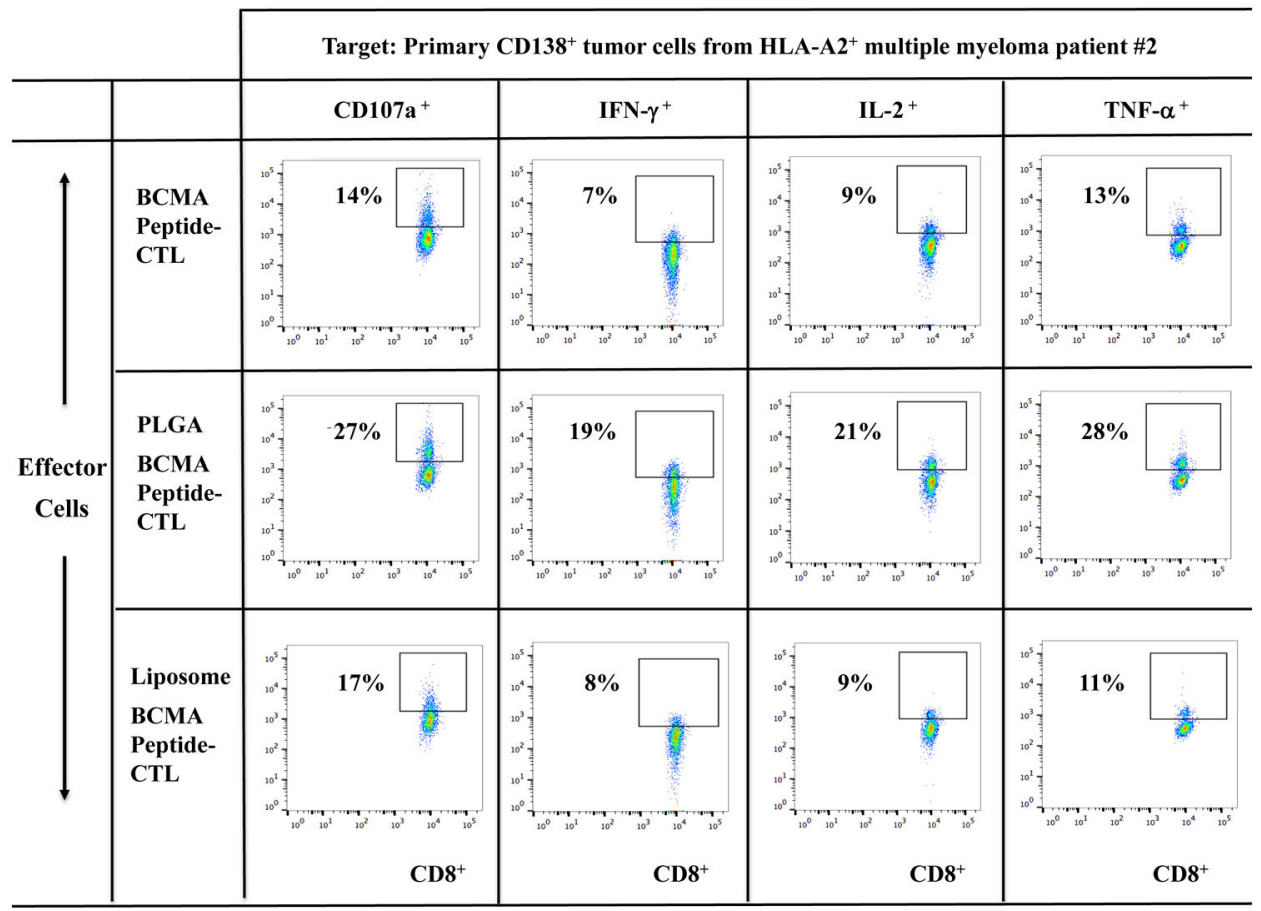

Leukemia. Author manuscript; available in PMC 2020 July 01. 

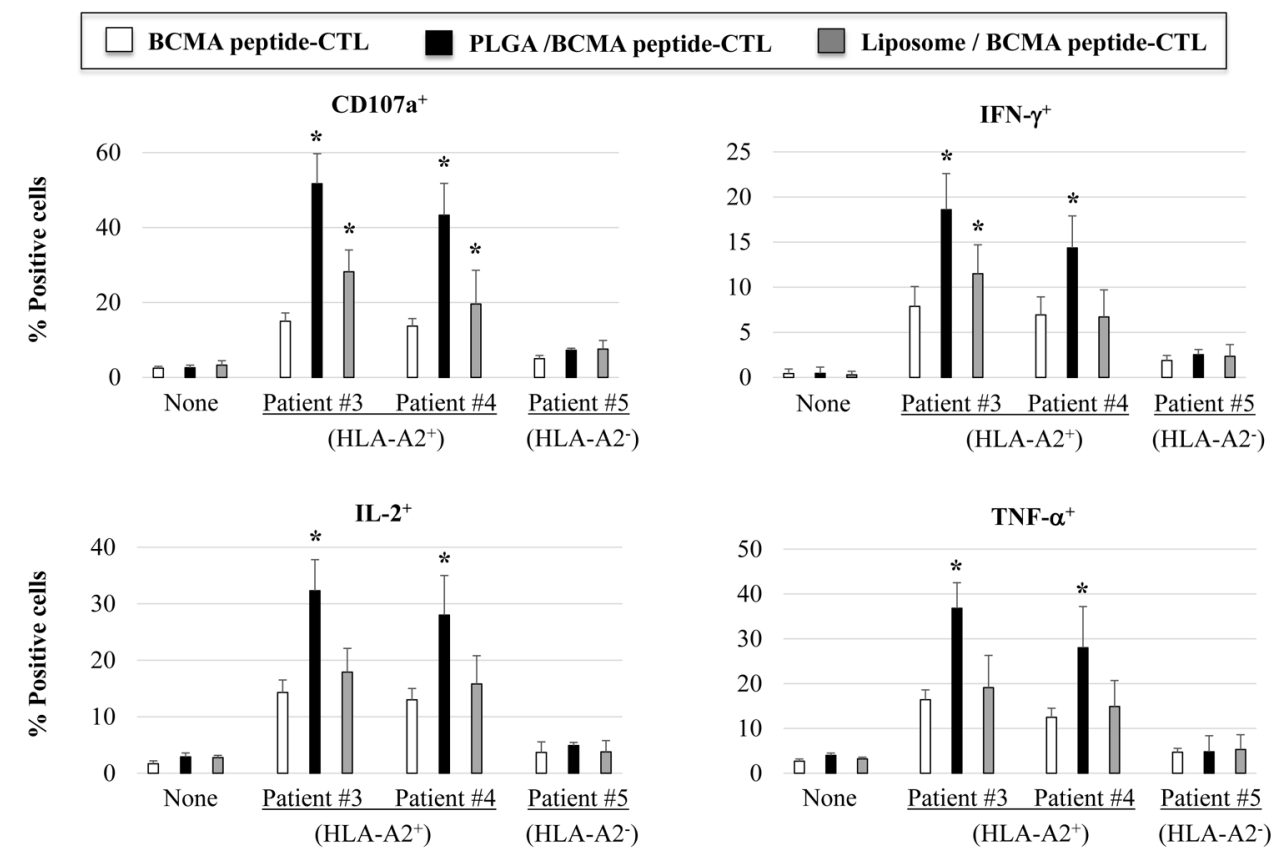

Target: CD138 ${ }^{+}$tumor cells from Myeloma Patients

Figure 4. Increased anti-MM activities of BCMA-specific CTL generated with BCMA72-80 peptide encapsulated nanoparticles against primary $\mathrm{CD138}^{+}$tumor cells from myeloma patients. A: Background functional activities by BCMA-CTL alone (no tumor cells encounted). B and C: Anti-MM activities of PLGA/peptide-CTL against primary CD138 $8^{+}$tumor cells from (B) HLA-A2 ${ }^{+}$MM Patient \#1 or from (C) HLA-A2 ${ }^{+}$MM Patient \#2. D: Summary of three independent experiments $(\mathrm{N}=3)$ showing the HLA-A2 restricted anti-tumor activities of BCMA-CTL against primary CD138+ tumor cells from myeloma patients. 

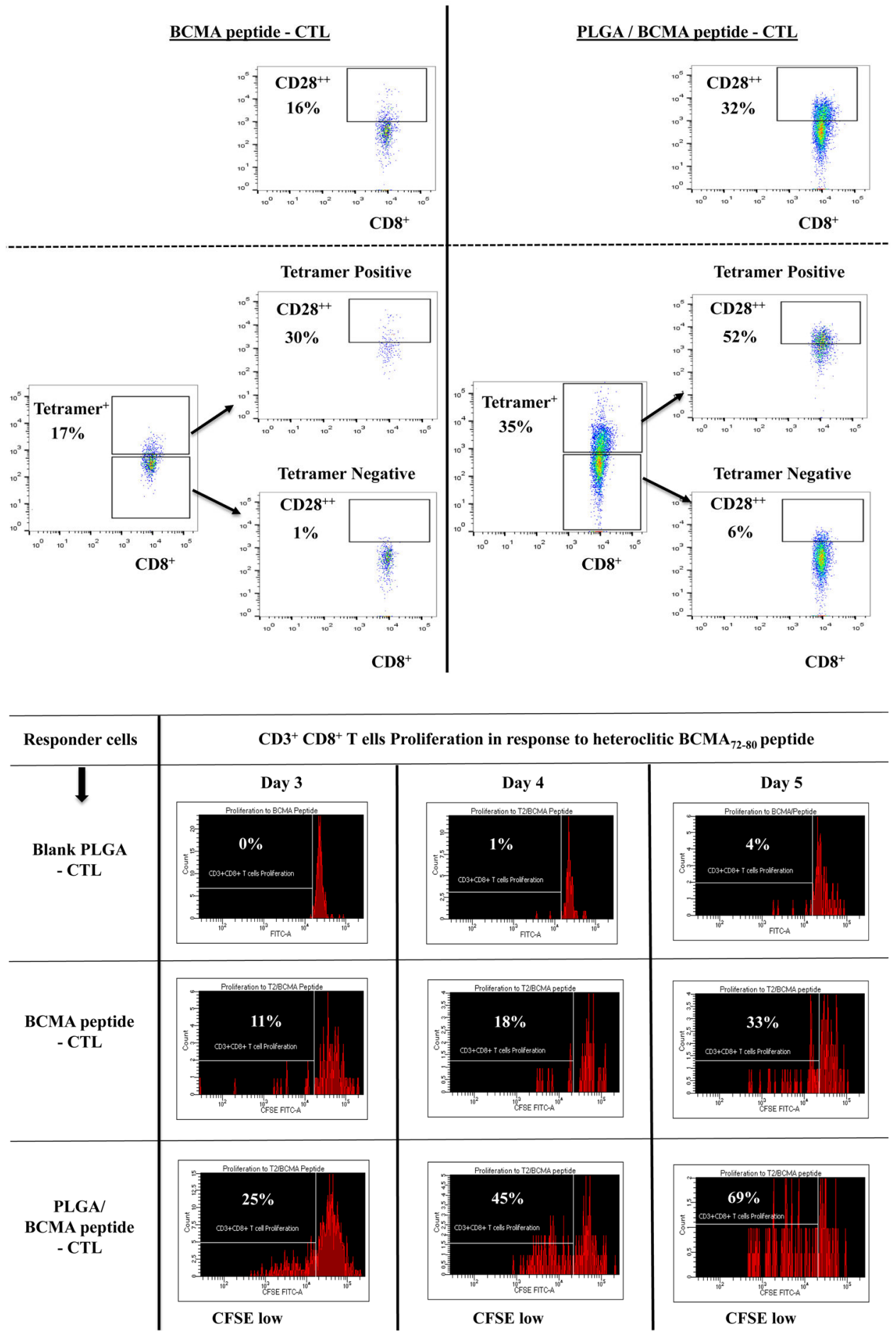

Leukemia. Author manuscript; available in PMC 2020 July 01. 


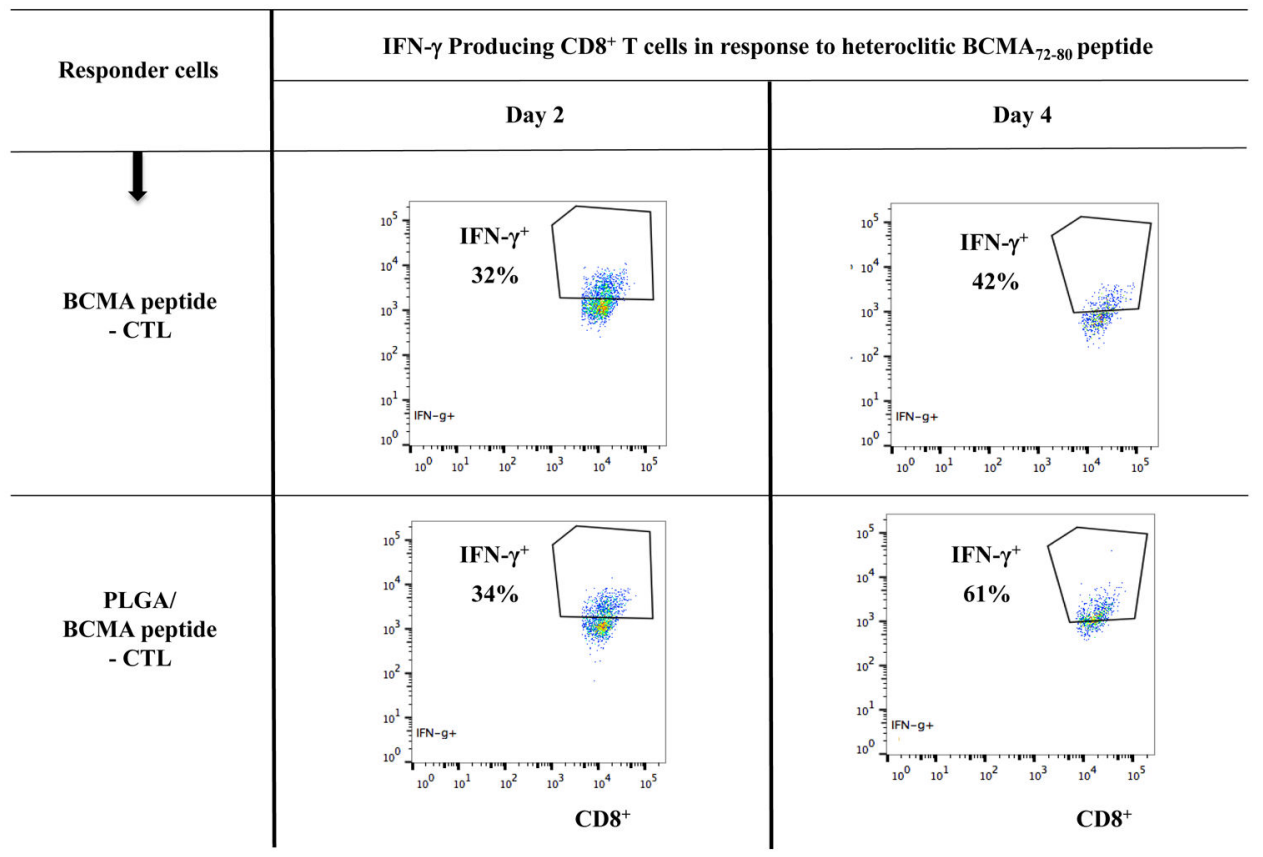

Figure 5. Increased frequency of $\mathrm{CD}^{+} 8^{+}$and Tetramer ${ }^{+} \mathrm{CTL}$, Th1-type cytokine production, and proliferation of $\mathrm{CDB}^{+} \mathrm{T}$ cells by PLGA/BCMA peptide-CTL.

A: Increased frequency of CD28 $8^{+}$(Top Panel) and BCMA-specific Tetramer ${ }^{+} \mathrm{CD} 8 \mathrm{~T}$ cells with CD28 upregulation (Bottom Panel) in PLGA/BCMA peptide-CTL. B: Increased proliferation $\left(\mathrm{CD}^{+} \mathrm{T}\right.$ cells gated) of PLGA/peptide-CTL in response to heteroclitic BCMA $_{72-80}$ peptide in a time-dependent manner (Day $5>$ Day $4>$ Day 3). C: Increased frequency of peptide-specific IFN- $\gamma^{+}$cells (CD8 ${ }^{+} \mathrm{T}$ cells gated) in PLGA/BCMA-CTL in response to heteroclitic $\mathrm{BCMA}_{72-80}$ peptide. 


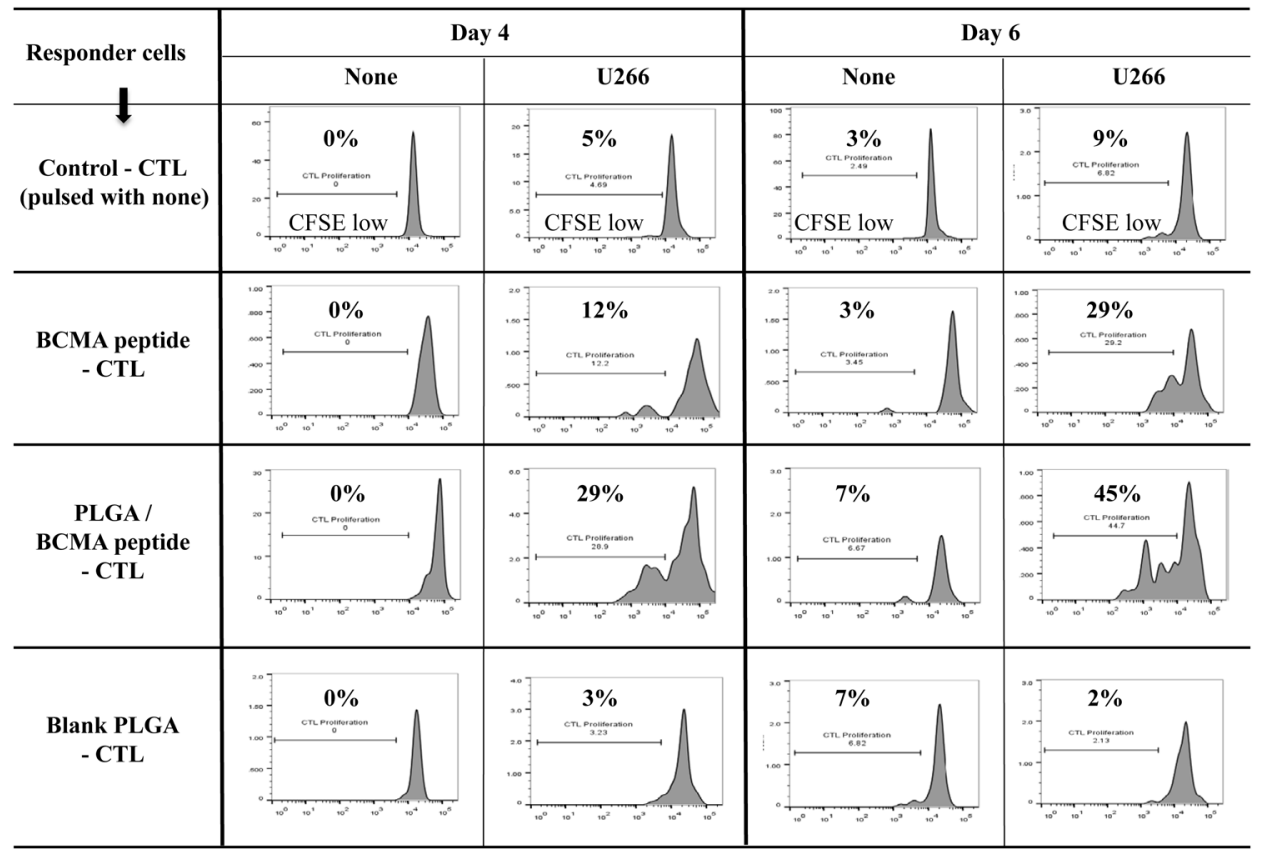

BCMA peptide-CTL

PLGA / BCMA peptide-CTL

$\% \mathrm{CD}^{2} 5 \mathrm{RO}^{+}$Memory $\mathrm{CD8}^{+} \mathrm{T}$ cells

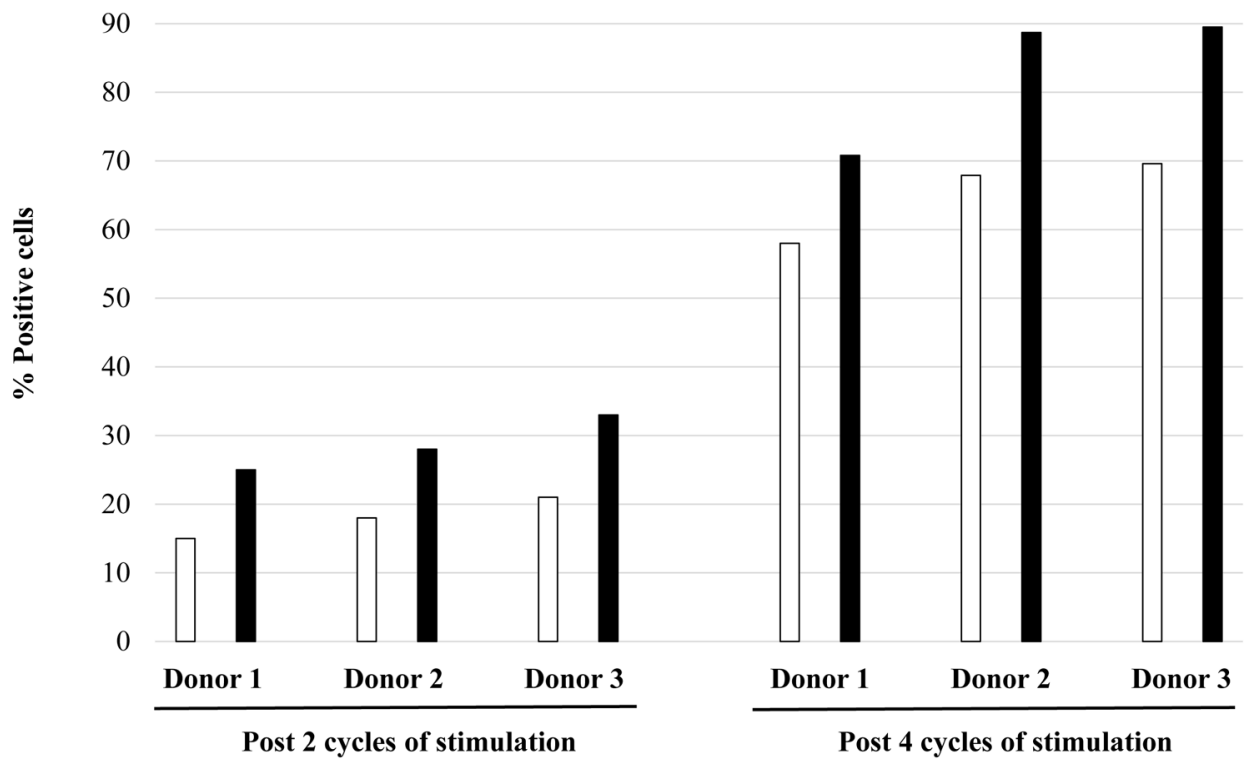

Leukemia. Author manuscript; available in PMC 2020 July 01. 


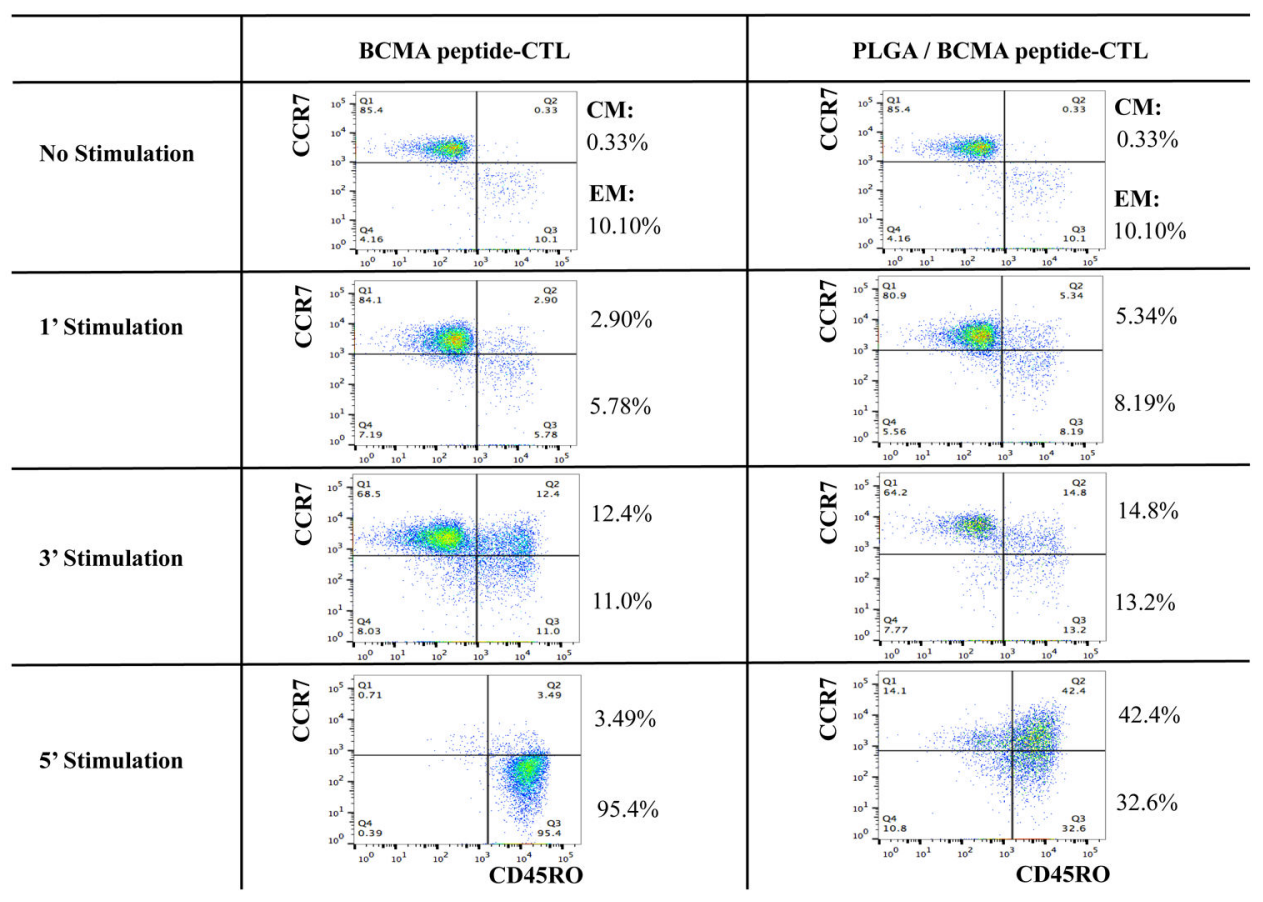

Figure 6. Increased memory cells with functional immune activities against myeloma cells in PLGA/BCMA peptide-CTL.

A: Increased $\mathrm{CD}^{+} \mathrm{T}$ cell proliferation in the PLGA/BCMA-CTL in response to HLA-A2 ${ }^{+}$ U266 MM cells (Day $6>$ Day 4). B: Increased induction of total CD45RO ${ }^{+}$memory CTL by PLGA/BCMA peptide than by free peptide, measured post-3, post-4 and post-5 cycles of stimulation. C: Summary of three independent experiments $(\mathrm{N}=3)$ demonstrating increased memory CTL induction by PLGA/peptide than by free peptide, measured post- 2 and post- 4 cycles of stimulation. D: Increased level of central memory and effector memory CTL generation by stimulation with PLGA/peptide than free peptide, measured post- 1 and post-3 cycles of stimulation. Increased maintenance of central memory cells was detected in BCMA-CTL generated by PLGA/peptide than free peptide, measured post-5 cycles of peptide stimulation. 

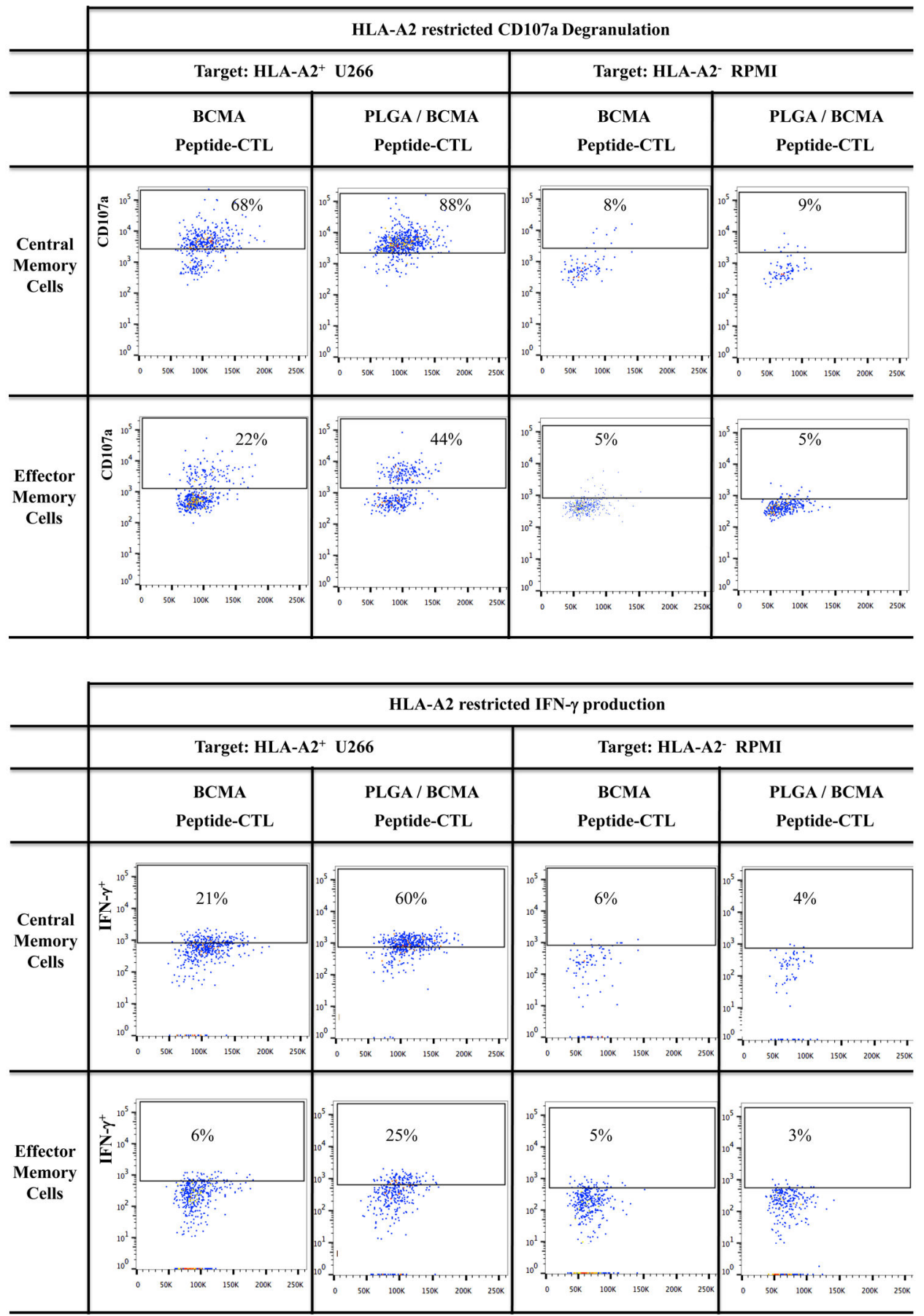

Leukemia. Author manuscript; available in PMC 2020 July 01. 
BCMA peptide-CTL

PLGA / BCMA peptide-CTL

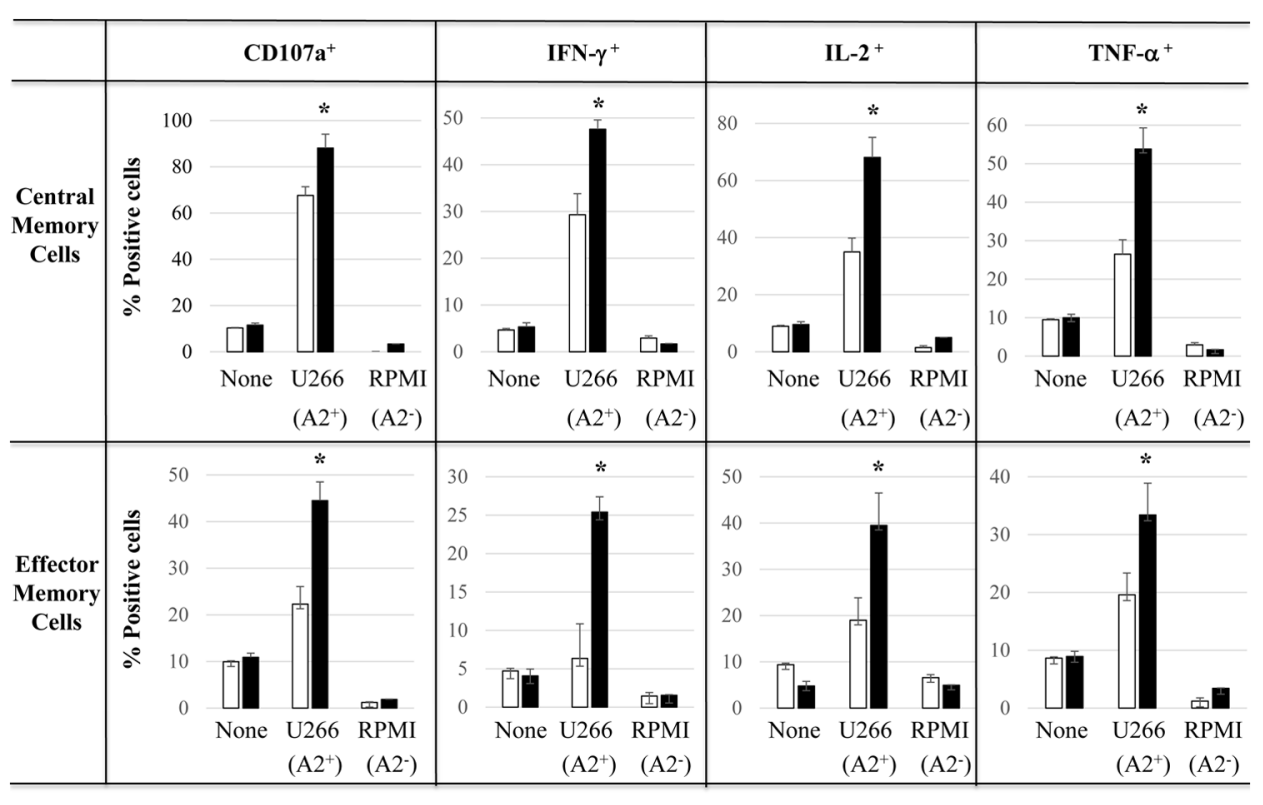

Target Cells

Figure 7. Increased anti-myeloma activities of BCMA-specific memory CTL generated with PLGA/BCMA peptide.

A and B: Increased anti-myeloma activities of BCMA-specific central memory and effector memory CTL generated with PLGA/peptide than free peptide, demonstrated by (A) CD107a degranulation and (B) IFN- $\gamma$ production, in response to HLA-A2 ${ }^{+}$myeloma cells (U266). C: Summary of three independent experiments $(\mathrm{N}=3)$ showing increased anti-myeloma activities (CD107a degranulation, IFN- $\gamma /$ IL-2/TNF-a cytokine production) by PLGA/ peptide-induced memory CTL $(\mathrm{CM}>\mathrm{EM})$ compared to free peptide-induced memory CTL. 